M. Stöhr, I. Boxx, C. D. Carter and W. Meier, Experimental study of vortexflame interaction in a gas turbine model combustor, Combustion and Flame 159 (2012) 2636-2649.

The original publication is available at www.elsevier.com

http://dx.doi.org/10.1016/j.combustflame.2012.03.020 


\title{
Experimental study of vortex-flame interaction in a gas turbine model combustor
}

\author{
M. Stöhr ${ }^{a, *}$, I. Boxx ${ }^{a}$, C. D. Carter ${ }^{b}$, W. Meier ${ }^{a}$ \\ ${ }^{a}$ German Aerospace Center (DLR), Institute of Combustion Technology, Pfaffenwaldring 38-40, 70569 Stuttgart, Germany \\ ${ }^{b}$ Air Force Research Laboratory, Wright-Patterson Air Force Base, Dayton, OH 45433, USA
}

\begin{abstract}
The interaction of a helical precessing vortex core (PVC) with turbulent swirl flames in a gas turbine model combustor is studied experimentally. The combustor is operated with air and methane at atmospheric pressure and thermal powers from 10 to $35 \mathrm{~kW}$. The flow field is measured using particle image velocimetry (PIV), and the dominant unsteady vortex structures are determined using proper orthogonal decomposition. For all operating conditions, a PVC is detected in the shear layer of the inner recirculation zone (IRZ). In addition, a co-rotating helical vortex in the outer shear layer (OSL) and a central vortex originating in the exhaust tube are found. OH chemiluminescence (CL) images show that the flames are mainly stabilized in the inner shear layer (ISL), where also the PVC is located. Phase-averaged images of $\mathrm{OH}-\mathrm{CL}$ show that for all conditions, a major part of heat release takes place in a helical zone that is coupled to the PVC. The mechanisms of the interaction between PVC and flame are then studied for the case $P=10 \mathrm{~kW}$ using simultaneous PIV and OH-PLIF measurements with a repetition rate of $5 \mathrm{kHz}$. The measurements show that the PVC causes a regular sequence of flame roll-up, mixing of burned and unburned gas, and subsequent ignition of the mixture in the ISL. These effects are directly linked to the periodic vortex motions. A phase-averaged analysis of the flow field further shows that the PVC induces an unsteady lower stagnation point that is not present in the average flow field. The motion of the stagnation point is linked to the periodic precession of the PVC. Near this point burned and unburned gas collide frontally and a significant amount of heat release takes place. The flame dynamics near this point is also coupled to the PVC. In this way, a part of the reaction zone is periodically drawn from the stagnation point into the ISL, and thus serves as an ignition source for the reactions in this layer. In total, the effects in the ISL and at the stagnation point showed that the PVC plays an essential role in the stabilization mechanism of the turbulent swirl flames. In contrast to the PVC, the vortices in the OSL and near the exhaust tube have no direct effect on the flame since they are located outside the flame zone.
\end{abstract}

Keywords: Gas turbine combustion, Turbulent swirl flame, Precessing Vortex Core, Laser diagnostics

\section{Introduction}

Modern gas turbine (GT) combustors are operated under lean premixed or partially premixed conditions in order to reduce emissions of $\mathrm{NO}_{x}$ and $\mathrm{CO}$. The highly turbulent flames in GT combustors are most often stabilized aerodynamically by swirl-induced vortex breakdown. This leads to recirculation of hot burned gases, which enhances ignition of unburned gas and thus helps to operate the flames under the desired lean conditions. The detailed mechanisms of the stabilization of turbulent swirl flames, however, are based on complex unsteady interactions of flow field and chemistry that are still not well enough understood today [1]. Further improvements of GT combustors with respect to emissions, fuel flexibility, and reliability therefore depend considerably on a better understanding of these interactions.

The flow field of turbulent swirl flames not only contains turbulent velocity fluctuations, but in many cases

*Corresponding author. Email: michael.stoehr@dlr.de

Preprint submitted to Combustion and flame also features unsteady coherent vortex structures. The most common coherent vortex structure in swirl combustors is the so-called precessing vortex core (PVC) [2]. A literature survey provided in Appendix A shows that PVCs are frequently encountered in GT-typical swirl combustors. Consequently, not only turbulence-chemistry interaction $[3,4,5]$ is important in swirl combustors, but also the interaction of coherent vortices with the flame. While flow pattern and frequency of PVCs have been frequently characterized, studies of their interaction with a flame are, however, limited to the pioneering works of Syred and coworkers $[6,7,8]$ and a study of Li and Gutmark [9]. Although these works could show some effects of the PVC on mixing and flame shape, the detailed mechanisms of the interaction remain largely unclear.

Many previous works have investigated vortex-flame interaction at a rather fundamental level (see, e.g., Refs. $[10,11,12,13]$ and references therein). In these works, interaction of a single vortex or a vortex pair with a flame front is studied under well-defined conditions. The studies revealed that a vortex can interact with a flame in 
numerous ways. E.g., the vortex can influence the flame through transport and mixing, leading to changes of local gas composition and temperature. Furthermore, vortical structures may induce an enlarged flame surface or lead to strain-induced local extinction. The magnitude of each effect strongly depends on various parameters like, e.g., local gas composition and temperature, relative size and orientation of flame front and vortex, and time scales of chemistry and flow. Conversely, the flame affects the vortex due to the expansion induced by heat release and leads to changes of flow parameters such as density and viscosity.

In highly turbulent GT-typical swirl flames, interaction of a vortex with the flame is much more complex than under the well-defined conditions of the fundamental studies referenced above. This is mainly owing to the irregular turbulent velocity fluctuations that are superimposed on the coherent vortex flow structure. The turbulent flow can lead to effects like unsteady strain, mixing and a change of local flame surface orientation that can then compete and interact with the effects of the coherent vortex. Under such conditions, the detailed mechanisms of vortex-flame interaction are not well understood, and further detailed experimental studies are required.

The objective of this work is to elucidate the interaction of large-scale coherent vortices within turbulent swirl flames in a GT-typical combustor by means of modern laser-based methods. In particular, novel high-speed laser techniques are applied for simultaneous measurements of flow field and flame structure with high temporal and spatial resolution, which provide detailed insights into the mechanisms of the interaction. The study uses a GT model combustor, which at certain operating conditions exhibits thermoacoustic oscillations. These oscillations have been subject of numerous previous experimental studies, where several diagnostic techniques have been applied such as Raman spectroscopy, PLIF, and PIV at repetition rates between $5 \mathrm{~Hz}$ and $5 \mathrm{kHz}$. Recent reviews of these works are provided by Boxx et al. [14] and Steinberg et al. [15]. In another work, where the same combustor was operated at a fuel-lean condition, Stöhr et al. have investigated the dynamics of lean blowout [16].

The present study, by contrast, focuses completely on the role of coherent vortex structures. The combustor is therefore operated at conditions where no blowout and virtually no thermoacoustic oscillations occur, while coherent vortices such as a PVC are present. The operating conditions cover a range of thermal power from $10 \mathrm{~kW}$ to 35 $\mathrm{kW}$. After a general characterization of the flames, the flow field with the coherent vortices is studied in detail using particle image velocimetry (PIV) and acoustic analysis. An important part of this study is the analysis of the flow field using proper orthogonal decomposition (POD). The usefulness of POD for the analysis of a PVC has been demonstrated in a recent publication [17]. In the second part, the interaction of vortex and flame is studied using simultaneous PIV and planar laser-induced fluorescence of $\mathrm{OH}$ with repetition rates up to $5 \mathrm{kHz}$.
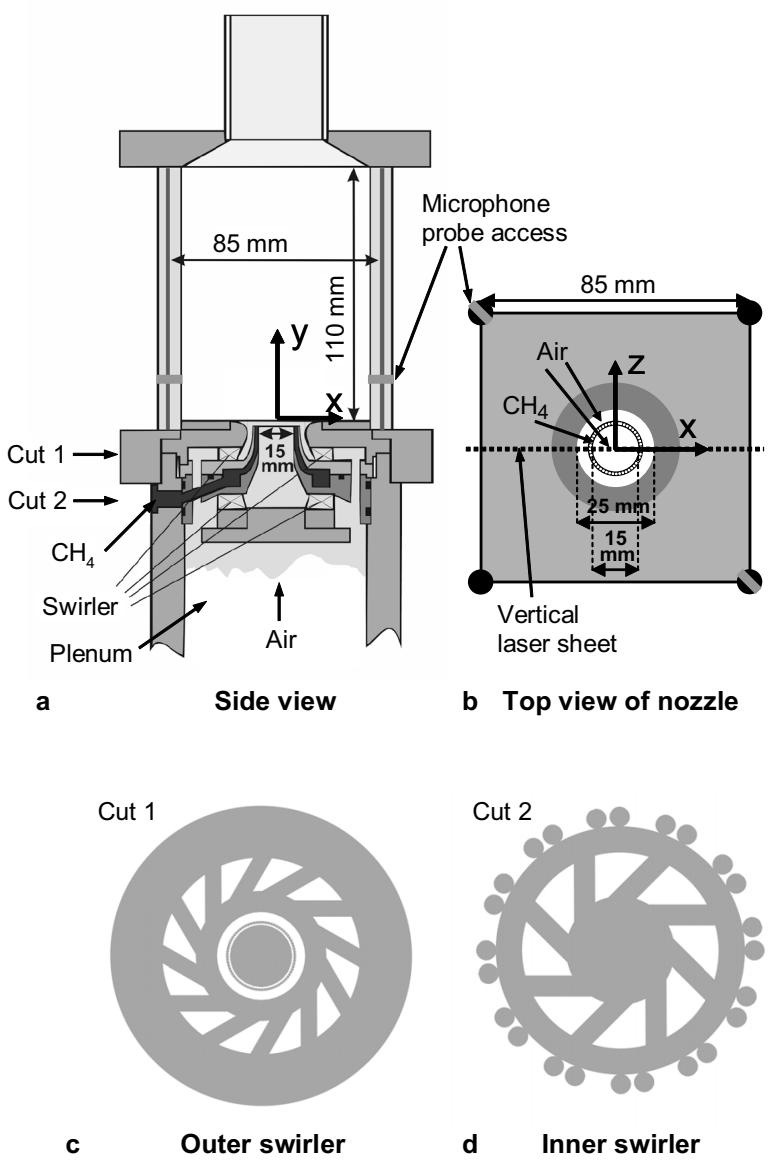

Figure 1: Geometry of the combustor (a) from the side and (b, c, d) in different horizontal views.

\section{Experimental methods}

\subsection{Combustor}

A sketch of the GT model combustor is shown in Fig. 1a. Dry air at ambient temperature enters the plenum (diameter $79 \mathrm{~mm}$, height $65 \mathrm{~mm}$ ) and then separately passes the inner (Fig. 1d) and outer (Fig. 1c) radial swirl generator. The two co-swirling flows enter the combustion chamber through a central circular nozzle (diameter 15 $\mathrm{mm}$ ) and a surrounding annular nozzle (inner diameter 17 $\mathrm{mm}$, outer diameter $25 \mathrm{~mm}$ contoured to an outer diameter of $40 \mathrm{~mm}$ ). Non-swirling gaseous fuel is supplied through 72 channels $\left(0.5 \times 0.5 \mathrm{~mm}^{2}\right)$ forming a ring between the air nozzles (Fig. 1b). The exit planes of the fuel and central air nozzles are located $4.5 \mathrm{~mm}$ below the exit plane of the outer air nozzle that is taken as height $y=0 \mathrm{~mm}$. The combustion chamber has a square cross-section of $85 \times 85$ $\mathrm{mm}^{2}$, a height of $114 \mathrm{~mm}$, and is enclosed by four quartz windows held by four posts (diameter $10 \mathrm{~mm}$ ) in the corners allowing very good optical access. A conical top plate with a central exhaust tube (diameter $40 \mathrm{~mm}$, length 50 $\mathrm{mm}$ ) forms the exit. 


\begin{tabular}{ccc}
$P[\mathrm{~kW}]$ & $\varphi$ & $\mathrm{Re}$ \\
\hline \hline 10 & 0.65 & 15000 \\
\hline 15 & 0.65 & 22500 \\
\hline 20 & 0.65 & 30000 \\
\hline 25 & 0.65 & 37500 \\
\hline 30 & 0.65 & 45000 \\
\hline 35 & 0.65 & 52500
\end{tabular}

Table 1: Operating conditions

\subsection{Operating conditions}

Six operating conditions with a global equivalence ratio $\varphi=0.65$ and thermal powers from $P=10 \mathrm{~kW}$ to $P=35 \mathrm{~kW}$ are studied (see Table 1). In all cases, the flame is operated with methane and air at atmospheric pressure. The corresponding Reynolds number of the unburned inflow ranges from $R e=15000$ to $R e=52500$. From velocity profiles at $y=1 \mathrm{~mm}$, the swirl number $S$, calculated as the ratio between the tangential and axial momentum flux, has been estimated in a previous work as $S \approx 0.55$ at $P=10 \mathrm{~kW}$ and $S \approx 0.9$ at $P=35 \mathrm{~kW}[18]$.

\subsection{Diagnostic techniques}

\subsubsection{Overview}

The experimental techniques used in this work have largely been detailed in previous publications, and therefore mostly brief descriptions of them will be provided here. Stereoscopic particle image velocimetry (PIV) was applied both separately with a repetition rate of $5 \mathrm{~Hz}$ (Sect. 2.3.2) and in combination with planar laser-induced fluorescence (PLIF) of OH (Sect. 2.3.3) at rate of $5 \mathrm{kHz}$. While the field of view of the $5 \mathrm{kHz}$ PIV system is limited to a region of $30 \times 30 \mathrm{~mm}^{2}$, the measurement domain of the $5 \mathrm{~Hz}$ system extends across the full width of the chamber. Furthermore, imaging of $\mathrm{OH}$ chemiluminescence (Sect. 2.3.4) and recording of pressure (Sect. 2.3.5) were performed.

\subsubsection{Stereoscopic PIV}

For all conditions listed in Table 1, three-component velocity fields were measured using a stereoscopic PIV system (FlowMaster, LaVision) with a repetition rate of 5 Hz. The system consisted of a frequency-doubled dualhead Nd:YAG laser (NewWave Solo 120, $120 \mathrm{~mJ}$ per pulse at $532 \mathrm{~nm}$ ), two double-shutter CCD cameras (LaVision Imager Intense, $1376 \times 1040$ pixels) and a programmable timing unit (PTU 9, LaVision).

The laser beam was expanded to a planar light sheet that covered the entire vertical section of the combustion chamber. The thickness of the laser sheet was around 1 $\mathrm{mm}$. The separation time between the two PIV frames was between $6 \mu \mathrm{s}(P=35 \mathrm{~kW})$ and $20 \mu \mathrm{s}(P=10 \mathrm{~kW})$. The cameras were equipped with a wide-angle lens $(f=16$ $\mathrm{mm}, f / 1.4)$ and a bandpass filter $(532 \pm 5 \mathrm{~nm})$ for reducing the influence of flame luminosity. Both cameras were mounted on Scheimpflug adapters in order to align their focal plane with the laser sheet. The two cameras were located as close as possible to the combustor in order to image the full vertical section of the chamber with a reasonably large stereoscopic angle. In the present configuration, the distance between the camera lenses and the measurement plane was $20 \mathrm{~cm}$, and the angle of view of the cameras to the $z$ axis was $20^{\circ}$. An infrared filter was mounted between the combustor and the cameras in order to protect the latter from thermal radiation.

The air flow was seeded with $\mathrm{TiO}_{2}$ particles with a diameter of $1 \mu \mathrm{m}$, which have a relaxation time of $\tau \approx 0.5 \cdot 10^{-5}$ $\mathrm{s}$. For the condition with the highest velocities $(P=35 \mathrm{~kW}$, velocity scale $v=80 \mathrm{~m} / \mathrm{s}$, length scale $l=10 \mathrm{~mm}$, cf. Fig. $6 \mathrm{~b})$, the resulting slip velocity is $\Delta v=\frac{\tau v^{2}}{2 l}=1.6 \mathrm{~m} / \mathrm{s}$, which corresponds to a (maximal) velocity error due to particle slip of $\frac{\Delta v}{v}=2 \%$.

Velocity fields were evaluated from particle images using a commercial PIV software (LaVision Davis 7.2). A multiscale cross-correlation algorithm was used with a final interrogation window size of $16 \times 16$ pixel (corresponding to an in-plane spatial resolution of $1.3 \times 1.3 \mathrm{~mm}^{2}$ ) and a window overlap of $50 \%$. Based on the \pm 0.1 pixel uncertainty of the peak-finding algorithm, the estimated random uncertainty of in-plane instantaneous velocities is ranging from $\pm 0.3 \mathrm{~m} / \mathrm{s}(P=10 \mathrm{~kW})$ to $\pm 1.4 \mathrm{~m} / \mathrm{s}(P=35 \mathrm{~kW})$. With the camera angle of $\alpha \approx 20^{\circ}$, the uncertainty of the out-of-plane velocity is about three times higher as for the in-plane uncertainty [19]. The same seed particles and algorithms for calculation of velocities were also used for the PIV systems combined with OH-PLIF.

\subsubsection{Simultaneous stereo-PIV and $\mathrm{OH}$-PLIF at $5 \mathrm{kHz}$}

For the case with $P=10 \mathrm{~kW}$ (Table 1), measurements were performed with a combined stereo-PIV and $\mathrm{OH}$ PLIF system operated at a repetition rate of $5 \mathrm{kHz}$. The stereo-PIV system was based on a dual-cavity Nd:YAG laser (Edgewave IS-611DE, $2.6 \mathrm{~mJ} /$ pulse at $532 \mathrm{~nm}$ after SHG) and a pair of CMOS cameras (LaVision HSS5, active sensor size $512 \times 512$ pixel) with $f=100 \mathrm{~mm}$ lenses $(f / 5.6)$. The OH-PLIF system consisted of a dye laser (Sirah Cobra-Stretch HRR, $100 \mu \mathrm{J} /$ pulse at $283.2 \mathrm{~nm}$ after SHG) pumped with a Nd:YLF laser (Edgewave IS-811E, $3.8 \mathrm{~mJ} /$ pulse at $523 \mathrm{~nm}$ after $\mathrm{SHG}$ ) and an intensified CMOS camera (LaVision HSS6,1024×1024 pixel with HSIRO) with a Cerco UV lens $(f=45 \mathrm{~mm}, f / 1.8)$. The wavelength of the dye laser was tuned to the peak of the isolated $\mathrm{Q}_{1}(7)$ line of the $\mathrm{A}-\mathrm{X}(1-0)$ transition of $\mathrm{OH}$, whose Boltzmann fraction of the lower state population changes about $10 \%$ in the range $\mathrm{T}=1200-2000 \mathrm{~K}$. The OH-PLIF excitation pulse was temporally interlaced between the two PIV pulses $(\Delta t=20 \mu \mathrm{s})$. The beams of the two laser systems were expanded into two coplanar vertical light sheets in the central vertical section $(z=0)$ of the combustion chamber. In the chamber, the thickness of the laser sheets was $0.7 \mathrm{~mm}$ and $0.4 \mathrm{~mm}$ for PIV and PLIF, respectively. While the field of view for the stereo-PIV was limited to a $30 \times 30$ 

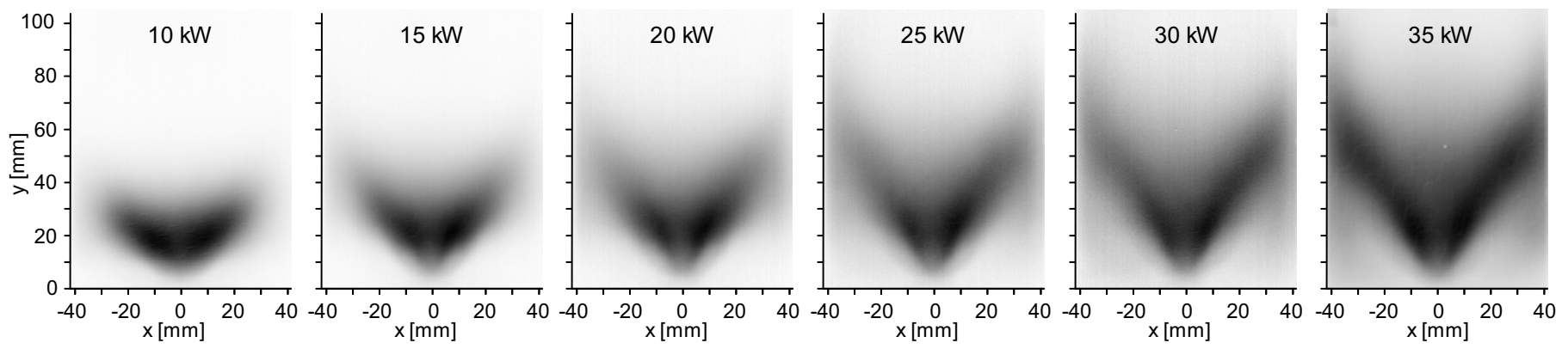

Figure 2: Average OHk chemiluminescence for different thermal powers at $\varphi=0.65$.

$\mathrm{mm}^{2}$ region above the nozzle, the OH-PLIF field extended across the full width and up to a height of $y=45 \mathrm{~mm}$. All cameras had sufficient on-board memory for at least 4096 individual recordings corresponding to an aquisition time of $0.8 \mathrm{~s}$. The velocity fields had an in-plane spatial resolution of $1.5 \times 1.5 \mathrm{~mm}^{2}$. Based on the \pm 0.1 pixel uncertainty of the peak-finding algorithm, the random uncertainty of in-plane instantaneous velocities is estimated as $\pm 0.5 \mathrm{~m} / \mathrm{s}$. The camera angles to the $z$ axis were $\alpha \approx 30^{\circ}$, and thus the uncertainty of the out-of-plane velocity is about twice as high as the in-plane uncertainty [19]. Other details about the system are provided in Ref. [14].

\subsubsection{Chemiluminescence imaging}

Line-of-sight integrated imaging of $\mathrm{OH}$ chemiluminescence (CL) was performed using an intensified CMOS camera (LaVision HSS8 with HS-IRO) equipped with a Cerco UV lens $(f=45 \mathrm{~mm}, f / 1.8)$ and a bandpass filter $(300325$ $\mathrm{nm})$. The field of view was the whole cross-section of the combustion chamber. The intensifier gate time and the frame rate varied from $40 \mu \mathrm{s}$ and $5 \mathrm{kHz}(P=10 \mathrm{~kW})$ to 12 $\mu$ s and $10 \mathrm{kHz}(P=35 \mathrm{~kW})$, respectively.

\subsubsection{Pressure recording}

Pressure signals from the combustion chamber have been recorded in order to determine the precession frequency of the PVC. Although this frequency can also be obtained from high-speed PIV measurements, the usage of the pressure signal is much easier for determining frequencies for a large number of operating conditions. Pressure in the chamber was measured using calibrated microphone probes equipped with B\&K Type 4939 condenser microphones. Two pressure signals, $p_{1}(t)$ and $p_{2}(t)$, are acquired from two opposite corners in the combustion chamber at a height of $y=15 \mathrm{~mm}$ (see Fig. 1a,b). The signals were recorded simultaneously using a multichannel A/D converter with a sampling rate of $100 \mathrm{kHz}$. As Sect. 4.6 will describe, the difference signal $\Delta p(t)=p_{1}(t)-p_{2}(t)$ contains the pressure history of the PVC, and is therefore used to determine the frequency and phase angle of the PVC precession. During optical measurements, the two pressure signals were recorded simultaneously with the trigger signal for lasers and cameras. The phase angle $\varphi$ with respect to the PVC precession can then be determined for each individual PIV, PLIF or OH-CL measurement.

\section{Average characteristics of the flames}

\subsection{Flame shape}

Figure 2 shows averaged $\mathrm{OH}^{*}$ chemiluminescence images of the flames with $\varphi=0.65$ and thermal powers from 10 to $35 \mathrm{~kW}$. The $\mathrm{OH}^{*}$ signal (integrated along the line-of-sight) is used as a marker of the locations of heat release [20]. At $P=10 \mathrm{~kW}$, the heat release zone lies between $y=5 \mathrm{~mm}$ and $y=45 \mathrm{~mm}$ in axial direction and within a radius of $r<35$ $\mathrm{mm}$ from the central axis. When thermal power and thus flow velocities are increased, the upper end of the flame zone gradually moves up to $y=100 \mathrm{~mm}$ for $P=35 \mathrm{~kW}$. For all thermal powers, the flame is not attached to the fuel nozzle exit, but stabilises at a height of $y \approx 5 \mathrm{~mm}$, which indicates that a high level of mixing occurs before ignition and that the flame therefore is of partially premixed nature (cf. Sect. 3.3).

\subsection{Velocity field}

Average flow fields in the vertical section $(z=0 \mathrm{~mm})$ are shown in Fig. 3 for $P=10 \mathrm{~kW}$ and $P=35 \mathrm{~kW}$. The color of the streamline plots represents the absolute value of velocity and the color in the vector plots shows the azimuthal velocity. The flow field is typical of confined swirl flames and consists of a cone-shaped stream of fresh gas entering the chamber from the burner nozzle, an inner recirculation zone (IRZ) and an outer recirculation zone (ORZ). Strong velocity gradients occur in the inner shear layer (ISL) between the inflow and the IRZ, and in the outer shear layer (OSL) between inflow and ORZ. High azimuthal velocities are found near the nozzle exit and near the exhaust duct contraction at the top. It can be seen that the structure of the average flow is largely independent of thermal power, except for a slight asymmetry that appears in the center of the IRZ at higher thermal power. It is further noted that in the average flow the lower stagnation point (LSP), i.e. the upstream boundary of the IRZ, is located below the measurement domain $(y<0 \mathrm{~mm})$. This is important 

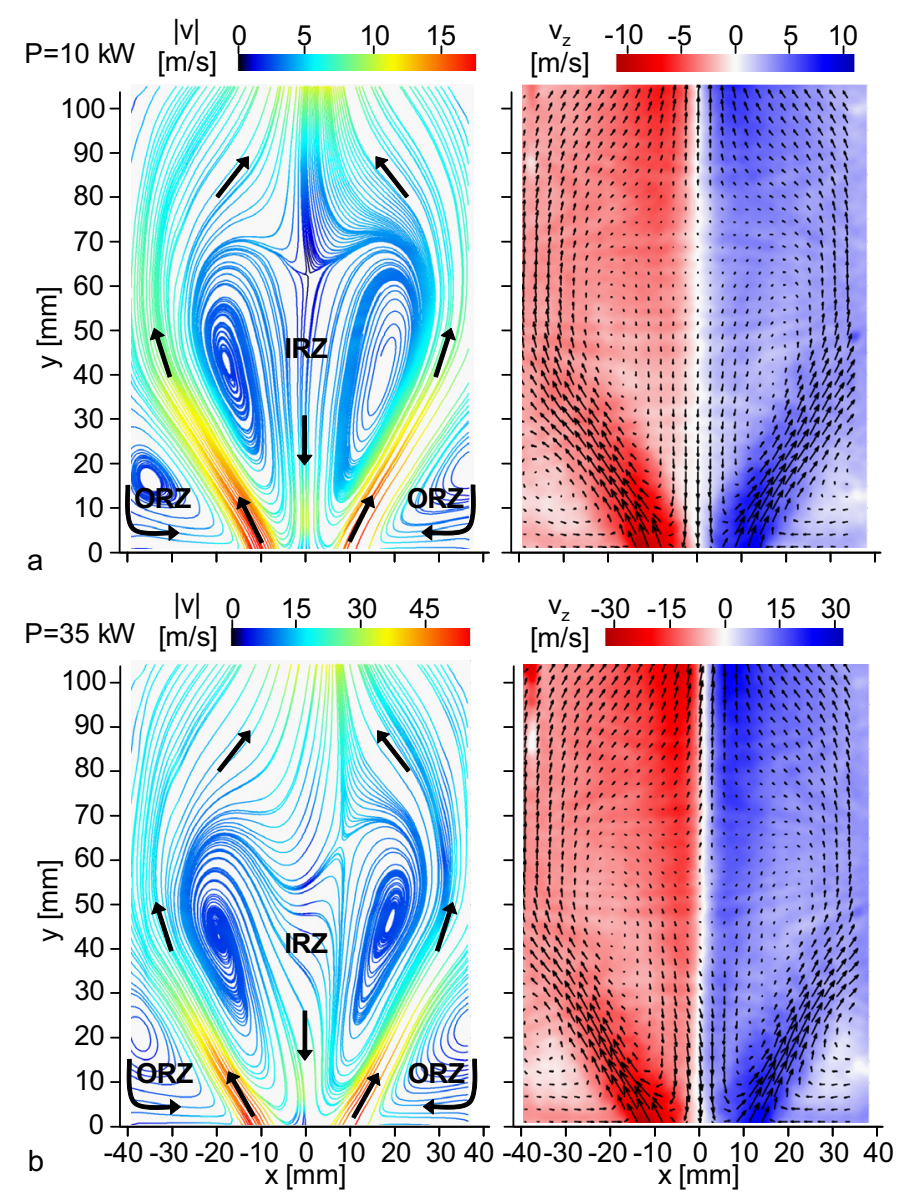

Figure 3: Average velocity fields for (a) $P=10 \mathrm{~kW}$ and (b) $P=35$ $\mathrm{kW}$. Colors represent absolute value of velocity (left) and azimuthal velocity (right).

with regard to the unsteady dynamics of the LSP and its relation to the PVC that will be discussed in sections 4.3 and 5.4.

Figure 4 shows the RMS values of the velocity field. Strong velocity fluctuations occur in the zones of high velocity gradients, namely the ISL and OSL. A second zone of strong velocity fluctuations is found along the centerline in the upper part of the chamber. These fluctuations are related to a vortex that forms in the exhaust duct contraction at the top and extends into the chamber (cf. Sect. 4.4). It can be seen that the length of this vortex increases with thermal power.

\subsection{Thermochemical state}

Distributions of average mixture fraction and temperature, which were measured in a previous study using Raman spectroscopy $[18,3]$, are shown in Fig. 5 for the flame with $P=35 \mathrm{~kW}$. The mixture fraction $f$ is the mass fraction in the measurement volume originating from the fuel nozzle. For methane and air, the stoichiometric value is $f_{\text {stoich }}=0.055$, and the value for $\varphi_{\text {global }}=0.65$ is $f_{\text {global }}=0.036$. It is seen that in the IRZ the gas com-

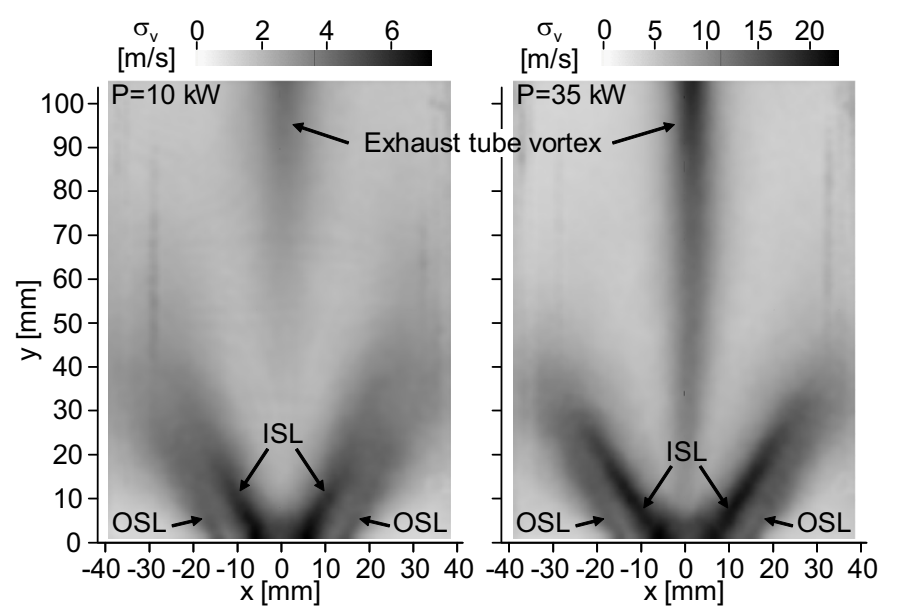

Figure 4: RMS values of the velocity field for $P=10 \mathrm{~kW}$ (left) and $P=35 \mathrm{~kW}$ (right).

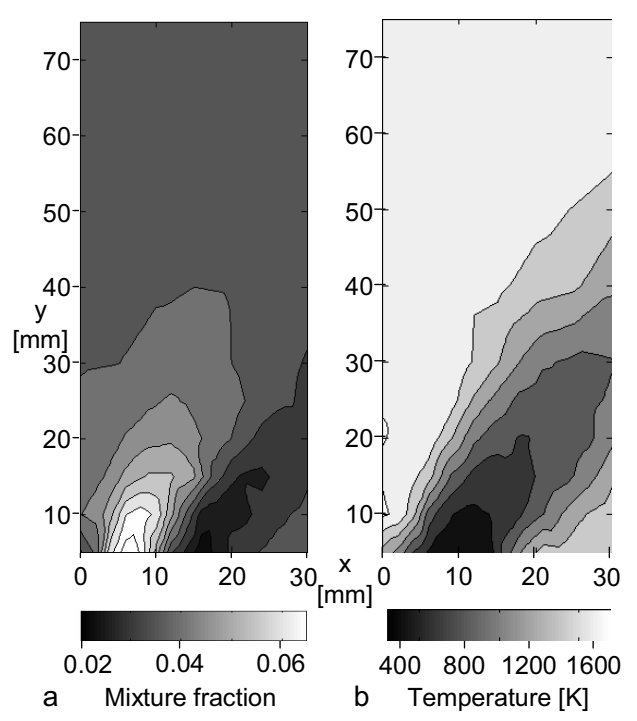

Figure 5: Average distributions of (a) mixture fraction and (b) temperature measured with Raman spectroscopy.

position is relatively fuel rich $f>f_{\text {global }}$, whereas in the ORZ the composition is relatively lean $f<f_{\text {global }}$. This is caused by the location of the fuel nozzles at $r=8 \mathrm{~mm}$. The effect is strongest at $y=5 \mathrm{~mm}$ (measurements were restricted to $y \geq 5 \mathrm{~mm}$ ), where values up to $f=0.07$ are encountered at $x=7 \mathrm{~mm}$, and decreases downstream due to mixing progress. It is further seen that at the beginning of the flame zone ( $y \approx 5 \mathrm{~mm}$ ), considerable mixing of fuel and air has taken place, and therefore the flame is of partially premixed nature.

Figure 5b shows the temperature increase within the jet flow region from $T=300 \mathrm{~K}$ at $y=5 \mathrm{~mm}$ to $T=1400 \mathrm{~K}$ at $y=40 \mathrm{~mm}$ as a result of reaction progress. The temperatures in the IRZ are higher than those in the ORZ, which results from the relatively rich and lean conditions, respectively. For a more detailed discussion of the ther- 

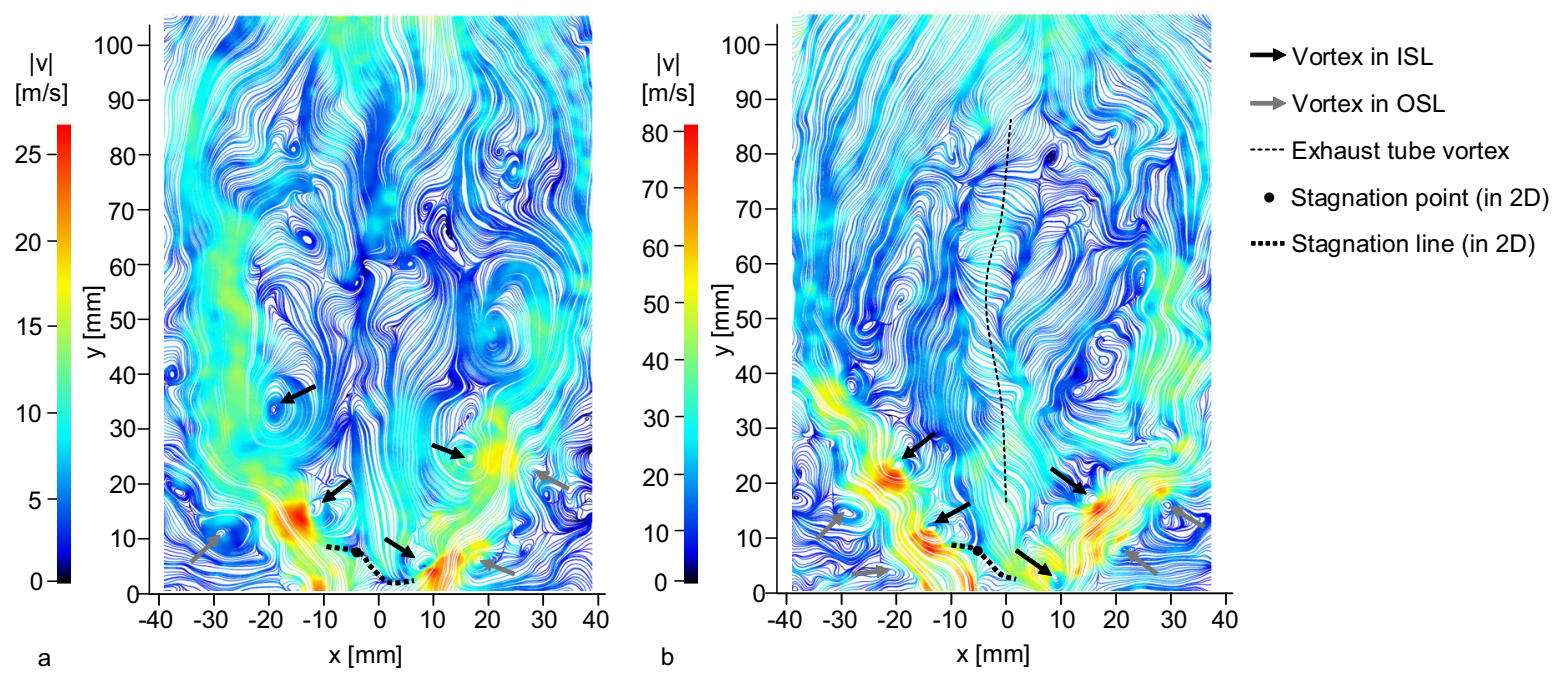

Figure 6: Instantaneous velocity fields for (a) $P=10 \mathrm{~kW}$ and (b) $P=35 \mathrm{~kW}$.

mochemical state of the flame, we refer to Refs. [18, 3].

\section{Characterization of the PVC}

\subsection{Instantaneous flow fields}

Figure 6 shows instantaneous velocity fields in the vertical section $(z=0 \mathrm{~mm})$ for $P=10 \mathrm{~kW}$ and $P=35 \mathrm{~kW}$. It can be seen that the instantaneous flow contains distinctive features that are not present in the average flow field. First, both instantaneous flow fields exhibit a zig-zag arrangement of vortices in the ISL marked by black arrows. This arrangement indicates the presence of a coherent 3D helical vortex in the ISL. Such a helical vortex is often found in swirl flames (cf. Appendix A) and is commonly termed a precessing vortex core (PVC). Furthermore, some more or less strong vortices appear in the OSL (marked by gray arrows) at positions that are obviously associated with the vortices in the ISL. The phase-averaged analysis in Sect. 4.3 will show that these vortices are part of a secondary helical vortex in the OSL, which co-rotates with the PVC around the central axis.

Another important element of the instantaneous flow are the stagnation point and the stagnation line above the nozzle exit, which are marked by red dots. In contrast to the average flow (Fig. 3), where the LSP is located below the dump plane $(y<0 \mathrm{~mm})$, the unsteady instantaneous LSP is typically found between $y=3 \mathrm{~mm}$ and $y=8 \mathrm{~mm}$ above the nozzle exit. In Sect. 4.3 it will be shown that the motion of the LSP is coupled to the vortex dynamics. The unsteady LSP plays an important role in the stabilization of the flames, which will be discussed in Sect. 5 .

\subsection{Proper orthogonal decomposition}

As it was seen in Sect. 4.1, the velocity field in the combustion chamber features different unsteady vortex structures as well as incoherent turbulent motions. Since the different phenomena are often superimposed on each other, it is not trivial to properly characterize the individual parts. It is therefore desirable to have available an appropriate statistical tool for analyzing the instantaneous flow fields. In the field of fluid mechanics, the analysis of flow fields using proper orthogonal decomposition (POD) has been established as a valuable tool for the extraction and characterization of coherent vortex structures [21]. The potential of POD to aid investigation of the PVC dynamics in the present combustor has been demonstrated in a recent work [17]. The same POD technique is used here to characterize the PVC for two flames, $P=10 \mathrm{~kW}$ and $P=35$ $\mathrm{kW}$. The main results are presented below, while details about the formalism and computational procedure can be found in [17].

For both flames, a snapshot POD of 600 instantaneous velocity fields $\vec{v}_{i}(\vec{x})(i=1 . .600)$ is performed. The result of the POD is a set of 600 POD modes $\vec{\phi}_{j}(\vec{x})(j=1 . .600)$. Generally, the POD modes represent the most dominant unsteady flow structures in terms of kinetic energy [21]. For the two flames investigated here, the three most dominant modes are shown in Fig. 7. The percentage values denote their contribution to the total turbulent kinetic energy in the measurement domain. It is seen that the first two modes represent vortex patterns in the ISL, whereas the third mode contains a vortex along the centerline in the upper part of the chamber (see also Fig. 4 and Sect. 4.4). The arrangement of vortices in the first two modes represents the coherent helical PVC in the ISL. The PVC is represented by two modes because of the precession of the PVC helix, which causes a periodic streamwise motion of vortices in the measuring plane. The vortex positions in the two modes are shifted with respect to each other by half of the distance between adjacent vortices. Any intermediate position of the vortices can be represented by an appropriately weighted linear combination of the two 

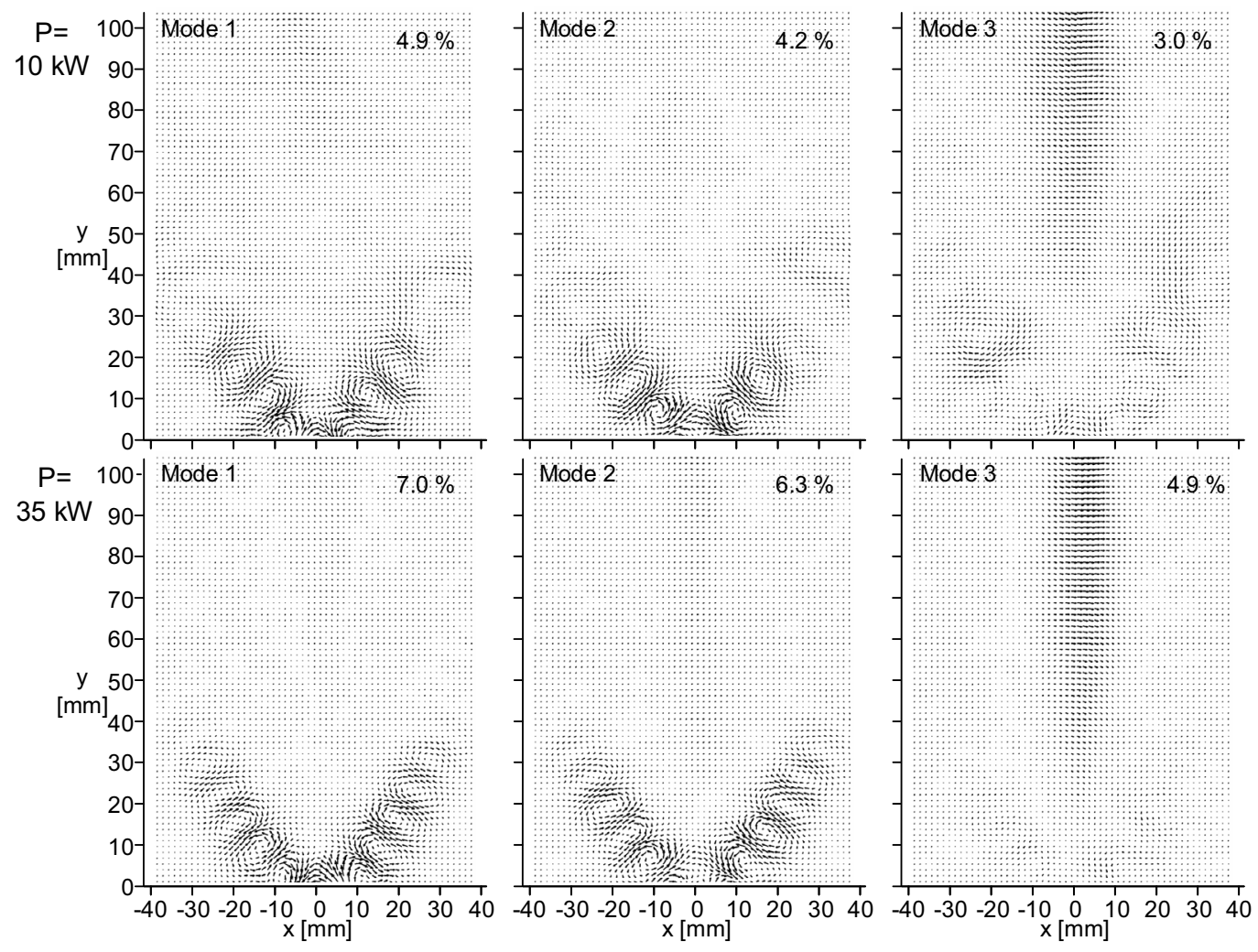

Figure 7: First 3 POD modes for $P=10 \mathrm{~kW}$ (top) and $P=35 \mathrm{~kW}$ (bottom).

modes. When this linear combination is superimposed on the average flow field, the characteristic zig-zag arrangement of vortices appears.

The relation between the vortex position and the relative weights of the first two modes can further be used to estimate the vortex position in each instantaneous velocity field $\vec{v}_{i}(\vec{x})$. The weight coefficients $a_{i 1}$ and $a_{i 2}$ can be calculated by taking the scalar product of $\vec{v}_{i}$ and $\vec{\phi}_{j}(j=1,2)$, and as shown in Ref. [17], the phase angle $\varphi_{i}$ of the PVC precession can estimated by

$$
\varphi_{i}=\frac{1}{\mathrm{i}} \ln \frac{a_{i 1}+\mathrm{i} a_{i 2}}{\sqrt{a_{i 1}^{2}+a_{i 2}^{2}}} .
$$

Subsequent to the estimation of the $\varphi_{i}$, phase-conditioned averages of the velocity field with respect to the PVC precession can be calculated. The results of this procedure are presented in the next section.

\subsection{Phase averages}

The instantaneous velocity fields discussed in Sect. 4.1 have already shown some effects of the PVC on the flow field. In the instantaneous velocity fields, however, the flow caused by the PVC is superimposed by turbulence and other unsteady dynamics (the PVC contributes only $9.1 \%$ and $13.3 \%$, respectively, to the velocity fluctuations, see Sect. 4.2). For a more rigorous analysis of the effect of the PVC, the velocity fields have therefore been conditionally averaged with respect to the phase angle $\varphi$ of the
PVC precession. In this way, all fluctuations that are not correlated to the phase of the PVC are canceled out. The phase averages were calculated using the POD mode coefficients as described in the previous section. For each of the 600 instantaneous measurements, $\varphi_{i}$ was determined according to Eq. 1, and averages were then calculated for eight phases $\left(0^{\circ} \pm 22.5^{\circ}, 45^{\circ} \pm 22.5^{\circ}, 90^{\circ} \pm 22.5^{\circ}, \ldots\right.$, $315^{\circ} \pm 22.5^{\circ}$.

The phase-averaged velocity fields at $\varphi=0^{\circ}, 45^{\circ}, 90^{\circ}$ and $135^{\circ}$ are shown in Fig. 8 for $P=10 \mathrm{~kW}$. The averages for $\varphi=180^{\circ}, 225^{\circ}, 270^{\circ}$ and $315^{\circ}$ are equivalent but mirrored at the central axis $(x=0 \mathrm{~mm})$. The view is limited to the region above the nozzle where most variations take place. The streamline plots show the regular downstream motion of vortices in the ISL, which corresponds to the precession of the PVC. The azimuthal velocity fields shown in the vector plots further indicate that the PVC leads to significant local variations of the swirling motion.

Another important feature is the dynamics of the stagnation points and the stagnation line, which are marked by red dots and lines. The stagnation line is the zone where the incoming flow $\left(v_{y}>0\right)$ and the recirculating flow from the IRZ $\left(v_{y}<0\right)$ frontally collide. Interestingly, the lower stagnation point (LSP) in the average flow (Fig. 3) is below the dump plane $(y<0)$, whereas in the phase averages it appears between $y=2 \mathrm{~mm}$ and $y=8 \mathrm{~mm}$. An additional stagnation point is found at $y \geq 8 \mathrm{~mm}$. This demonstrates that the PVC induces distinct unsteady stagnation points 


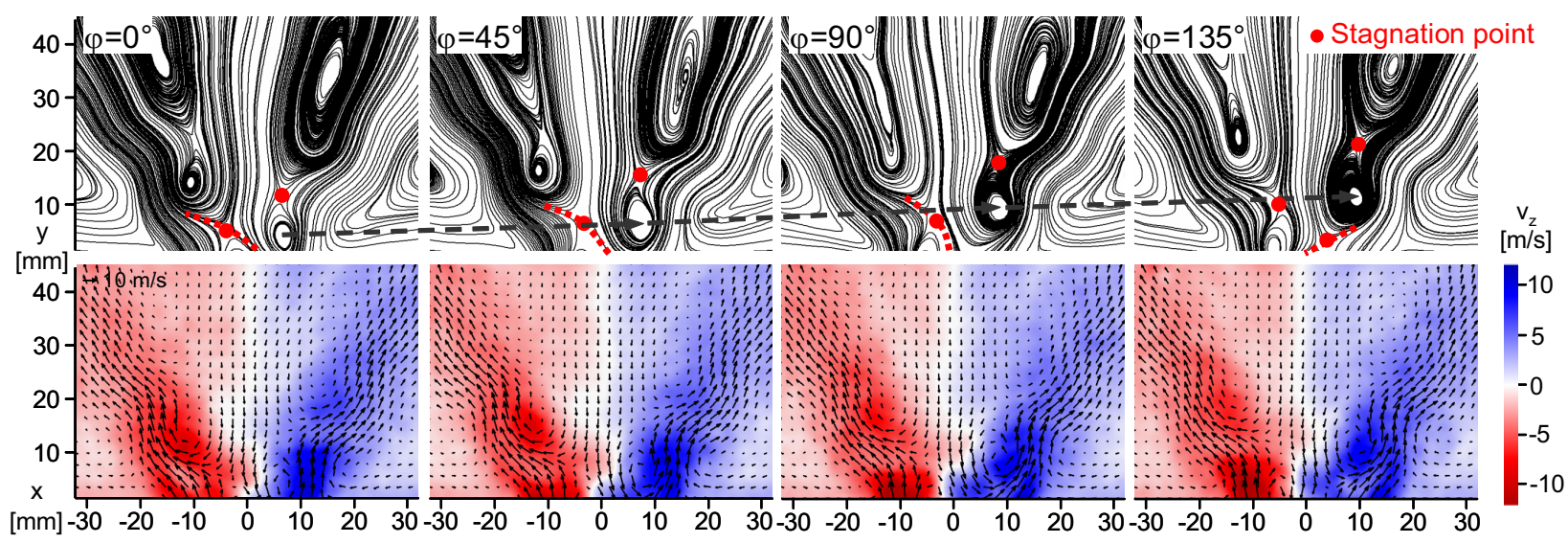

Figure 8: Phase averages of velocity field: Streamline plots (top) and vector plots with azimuthal velocity (bottom).

whose dynamics is coupled to the vortex motions. In Sect. 5 it will be shown that the stagnation points play an important role in flame stabilization.

\subsection{D structure}

Since the PVC performs a rotational motion around the central axis, the phase angle $\varphi$ corresponds to the azimuth of a cylindrical coordinate system. It is therefore possible to determine the 3D flow structure of the PVC by assembling the phase-averaged $2 \mathrm{D}$ velocity fields as sketched in Fig. 9a. The result is a $3 \mathrm{D}$, three-component velocity field that covers most part $(r \leq 38 \mathrm{~mm}, 1 \mathrm{~mm} \leq y \leq 106 \mathrm{~mm})$ of the combustion chamber. The dynamics of the PVC corresponds to a rotation of this velocity field around the central axis.

The resulting $3 \mathrm{D}$ velocity fields are discussed in the following for $P=10 \mathrm{~kW}$ and $P=35 \mathrm{~kW}$. The focus is on the visualization of vortical structures using a vortex identification technique. For the other flames $(P=15,20,25$ and $30 \mathrm{~kW}$ ), the shape of the observed vortex structures change gradually between the two cases. In a first step, the $3 \times 3$ velocity gradient tensor $D(\vec{x})=\vec{\nabla} \vec{v}(\vec{x})$ is calculated. From this tensor the swirling strength $\lambda$, which is a common vortex identification parameter [22], is determined. As first described by Zhou et al. [23], $\lambda$ is given by the imaginary part of the complex conjugate eigenvalues of $D$.

For the two flames, isosurfaces of $\lambda$ are shown in Fig. $9 \mathrm{~b}, \mathrm{c}$. In both cases, three coherent vortices can be seen. The first one is the helical PVC in the ISL. While the overall structure of the PVC is similar for both cases, the length and slope of the vortex core are somewhat different. At $P=10 \mathrm{~kW}$, the PVC makes $\approx 11 / 4$ revolutions and ends at $y \approx 25 \mathrm{~mm}$, whereas at $P=35 \mathrm{~kW}, \approx 21 / 4$ revolutions take place until the end at $y \approx 35 \mathrm{~mm}$.

A second helical vortex is found that is located in the OSL along the PVC. The corresponding $2 \mathrm{D}$ vortices in the OSL have already been seen in the instantaneous velocity fields shown in Fig. 6 (gray arrows). The fact that the secondary vortex appears in the phase averages of the PVC shows that both helical vortices are co-rotating around the centerline.

A third vortex appears along the centerline starting at the top of the chamber. This vortex forms in the exhaust tube contraction at the top and extends from there into the chamber. The length of the vortex increases with thermal power, and covers all the way to the bottom at $P=35$ $\mathrm{kW}$. The exhaust tube vortex has already been seen in the RMS values of velocity (Fig. 4) and in the third mode of the POD (Fig. 7). At $P=35 \mathrm{~kW}$, it is also visible in the instantaneous flow field (Fig. 6b). Furthermore, this type of vortex has been found in other swirl combustors $[24,25,26]$. As seen in Fig. 6b, this vortex can locally deviate from the centerline, and may thus also perform a slightly precessing motion. Therefore, care must be taken that this vortex is not mistaken with the PVC.

\subsection{Characterization of vortex core and outer zone}

Previous studies of vortex-flame interaction have shown that the effect of a vortex on a flame depends in large part on the vortex radius $R$ and the corresponding velocity $u(R)[27,10]$. In order to allow for comparison with other studies of vortex-flame interaction in the literature, it is desirable to determine these parameters for the present PVC.

For the case $P=10 \mathrm{~kW}$, Fig. 10a shows the flow field in a slice perpendicular to the vortex axis. Here, $x^{\prime}$ and $y^{\prime}$ are the coordinates relative to the vortex center. To the left and right of the vortex center, the reverse flow in the IRZ and the stream from the nozzle, respectively, can be seen. The velocity profile across the vortex at $y^{\prime}=0$ is plotted in Fig. 10b. The profile shows the typical features of a vortex in a viscous flow, namely an inner core characterized by solid-body rotation (marked with the dashed red line), and an outer zone where velocities decrease with distance from the center ("differential rotation"). The location of the maximum circumferential velocity $u(R)$ at the border between these two zones defines the vortex radius $R$. The 

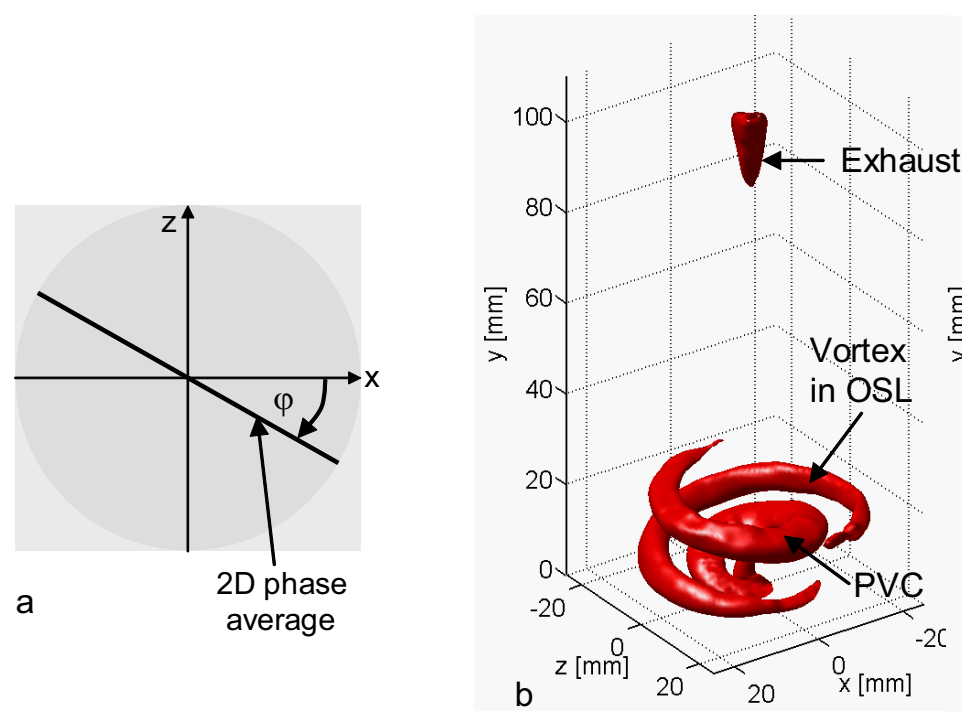

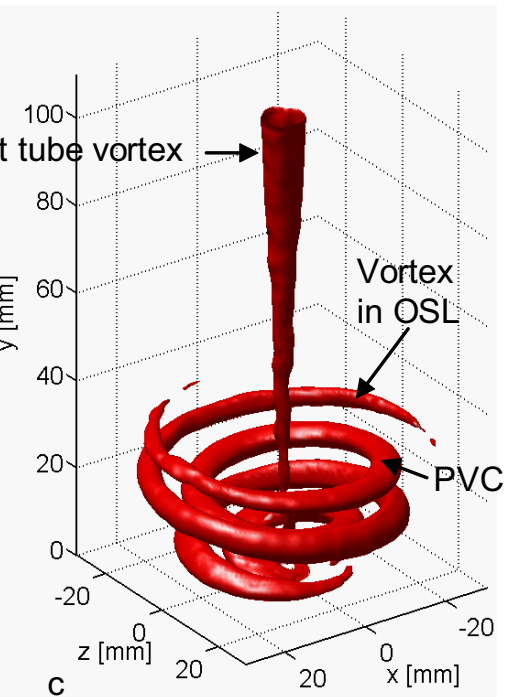

Figure 9: 3D reconstruction of vortex structures for (b) $P=10 \mathrm{~kW}$ and (c) $P=35 \mathrm{~kW}$.
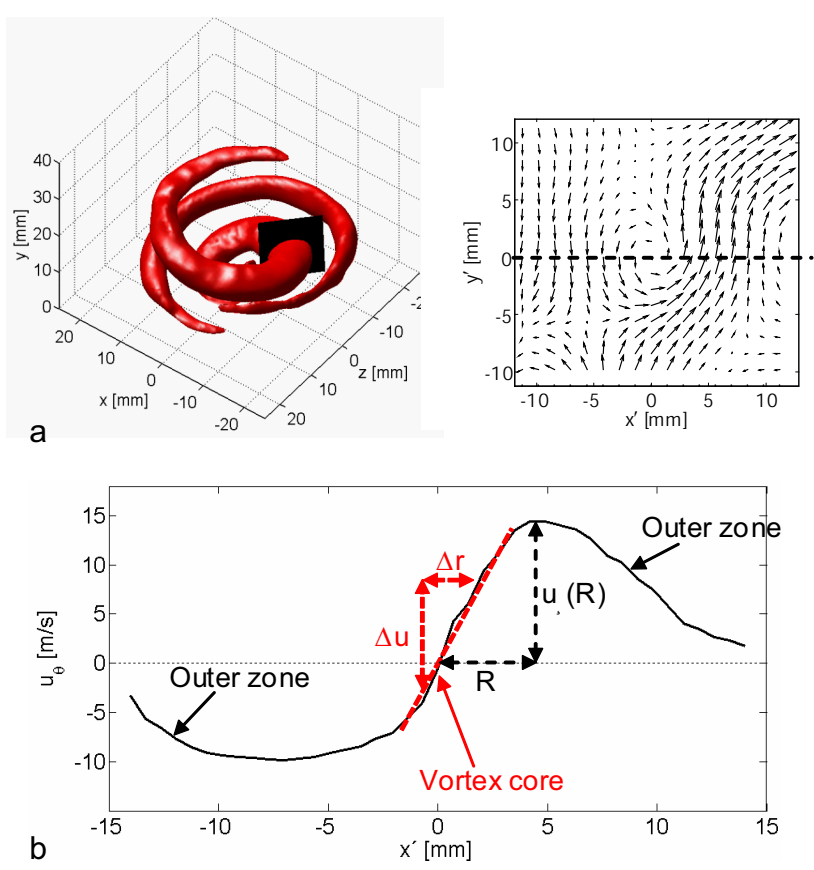

Figure 10: (a) Velocity field in a section across the PVC, (b) velocity profile across the vortex $\left(y^{\prime}=0 \mathrm{~mm}\right)$. core is further characterized by its rotational frequency $f_{\text {core }}=\frac{\Delta u_{\theta}}{2 \pi \Delta x^{\prime}}$.

The potential effects of the two zones on the flame are radically different. In the inner core, velocity gradients and thus strain rates are very low, which is favorable to the flame. Indeed it has been shown that a flame can propagate along a vortex core even faster than in a quiescent mixture $[28,29]$. In the outer zone, on the other hand, strong velocity gradients are present owing to the differential rotation. Depending on the relative orientation of flame front and vortex axis, these gradients may lead to increased rates of mixing and reaction $[30,31,32,33,34,10]$ or to local extinction due to flame stretch $[35,10]$. The determination of $R, u(R)$ and $f_{\text {core }}$ is therefore important for the analysis of the PVC-flame interaction in Sect. 5.

For the cases $P=10,20$ and $35 \mathrm{~kW}$, the evolutions of $R$, $u(R)$ and $f_{\text {core }}$ along the PVC are plotted in Fig. 11. For all cases, the radius $R$ is in the range of 3 to $6 \mathrm{~mm}$. The increase of $R$ along the PVC, however, is much stronger for $P=10 \mathrm{~kW}$ than for $P=20$ and $35 \mathrm{~kW}$. This may be caused by dilatation due to heat release (Sect. 5 ) at $P=10 \mathrm{~kW}$, which is reduced for $P=20$ and $35 \mathrm{~kW}$ [43]. The velocity $u(R)$ and the core frequency $f_{\text {core }}$, by contrast, increase with thermal power and decrease along the PVC.

\subsection{Precession frequency}

In contrast to the rotational frequency of the vortex core, the frequency of the PVC precession is typically the same throughout the combustor [2]. For the present burner it was found that this frequency can be determined using the pressure signals $p_{1}(t)$ and $p_{2}(t)$, which were measured with two probes at opposite corners of the combustion chamber as described in Sect. 2.3.5. As an example, Fig. 12a shows power spectra measured from a flame with $P=5$ $\mathrm{kW}$ and $\varphi=0.65$. In addition to the spectra for $p_{1}(t)$ and 

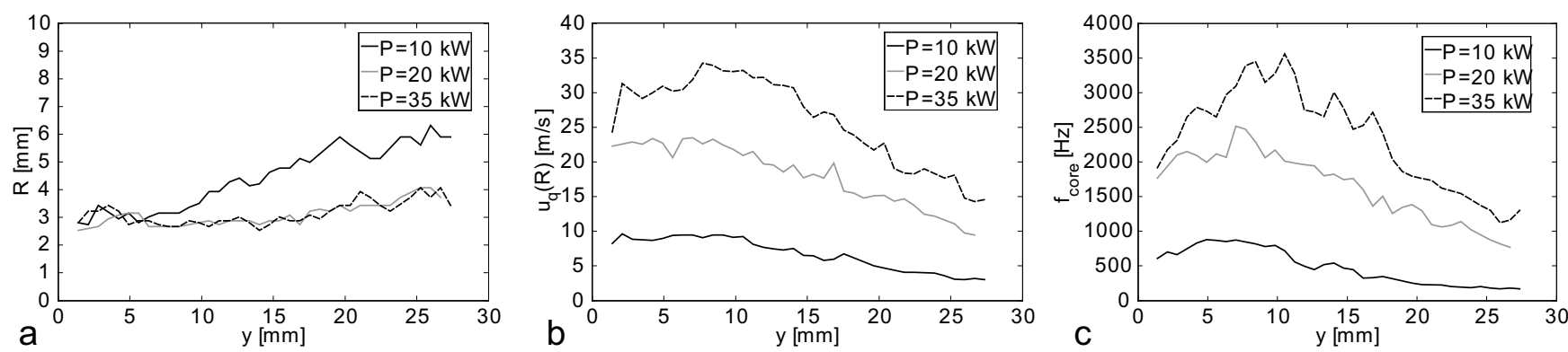

Figure 11: Evolutions along the PVC of (a) vortex core radius, (b) maximum tangential velocity and (c) core rotation frequency.

$p_{2}(t)$, the figure also shows the spectrum of the difference signal $\Delta p(t)=p_{1}(t)-p_{2}(t)$. The separate spectra of the two probes are almost equal, and exhibit a broad emission range with pressure levels $>85 \mathrm{~dB}$ from about 100 to 700 Hz. There are a few minor peaks and bumps, but there is no strong peak that can be clearly linked to the PVC. In the spectrum of the difference signal, in contrast, the broad-band emissions are mostly cancelled out, and a single clear peak remains at $f=270 \mathrm{~Hz}$. For flames where high-speed PIV measurements are available, a comparison of vortex dynamics and pressure signals shows that the peak in the difference spectrum corresponds to the precession of the PVC. The fact that the pressure signal from the $\mathrm{PVC}$ is not cancelled out in the difference signal $\Delta p(t)$ indicates that it originates from an off-axis location rotating around the center, whereas the broadband emissions are mostly axisymmetric.

Figure $12 \mathrm{~b}$ shows the measured frequencies for flames with $\varphi=0.65$ and thermal power from $5 \mathrm{~kW}$ to $35 \mathrm{~kW}$. It can be seen that the frequency increases almost linearly with the air flow rate with a slight decrease towards higher flow rates. The linear increase is typical for PVCs and has been reported in several other studies $[37,9,2,36]$. Based on the minimum outer diameter of the nozzle $(d=25 \mathrm{~mm})$, the corresponding Strouhal number is $\mathrm{St}=1.35$.

The PVC is also present in the corresponding nonreacting flows, where frequencies have been measured with the same method. Fig. 12b shows that the frequencies in the non-reacting cases are only slightly lower than for reacting conditions. Thermal expansion due to combustion leads to a strong increase of flow velocities, and therefore could lead to higher PVC frequencies. The observation that the frequencies do not change significantly therefore indicates that under reacting conditions the PVC is mostly located in the regions of unburned reactants within the flame zone. This is confirmed by the PIV and OH-PLIF measurements discussed in Sect. 5 (see, e.g., Figs. 14 or 17).
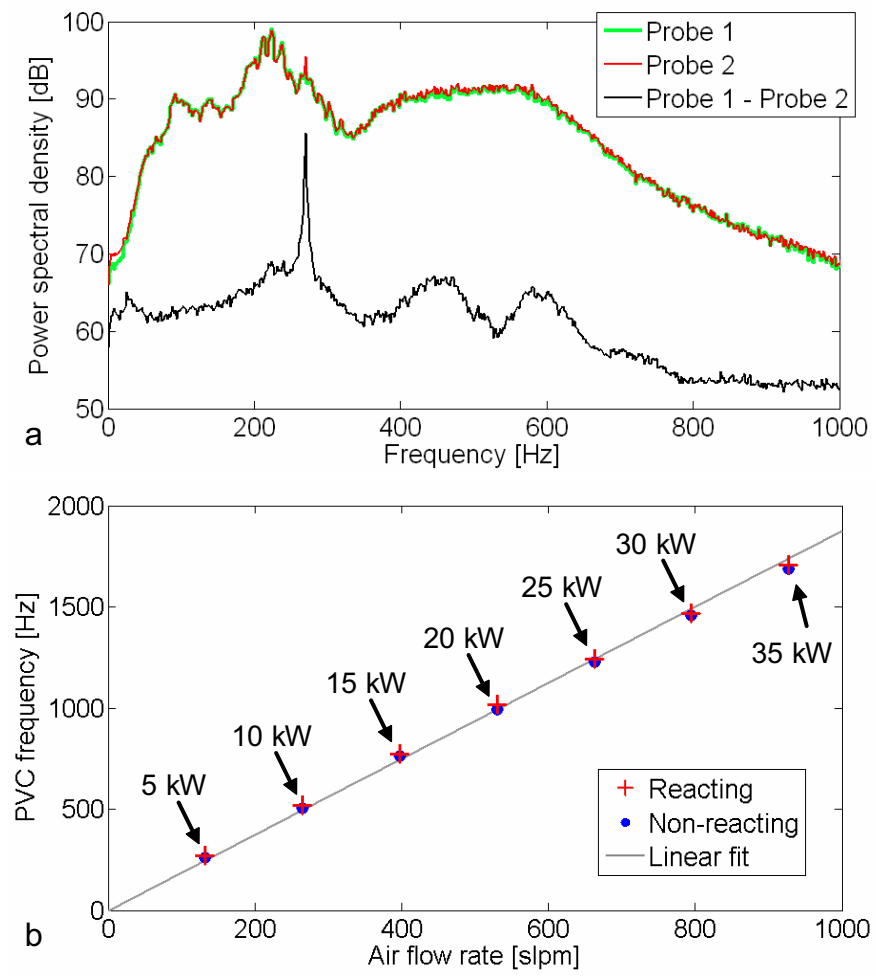

Figure 12: (a) Measured pressure spectra for $P=5 \mathrm{~kW}$, (b) Frequencies of $\mathrm{PVC}$ precession as a function of air flow rate. 

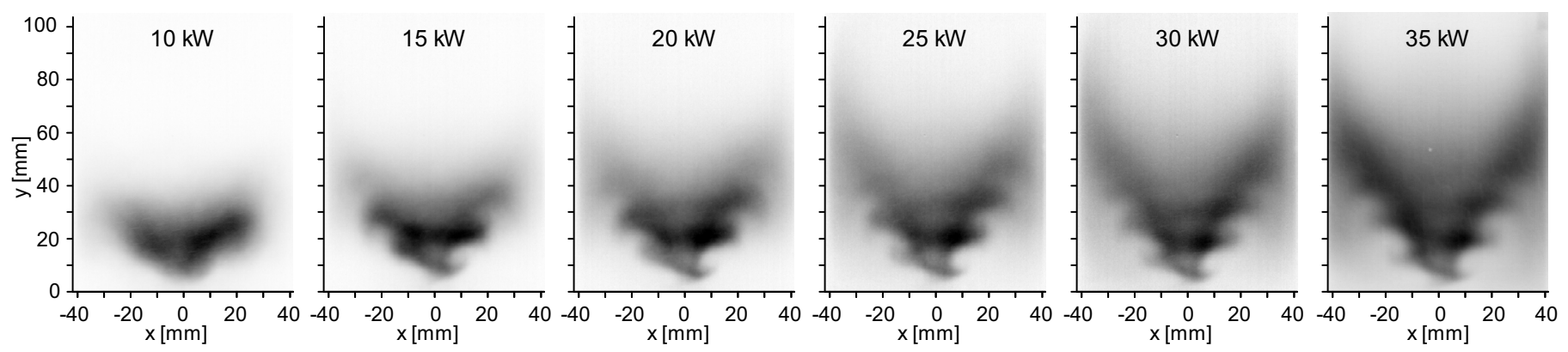

Figure 13: Phase-averaged $\mathrm{OH}$ chemiluminescence for different thermal powers at $\varphi=0.65$.

\section{Interaction of PVC and flame}

\subsection{General remarks}

The aim of this section is to characterize the effects of the PVC on the flame and its role in the mechanism of flame stabilization. For all conditions, the flame is stabilized in the ISL, where also the PVC is located. This suggests that the PVC may strongly interact with the flame. In contrast, the vortex in the OSL and the exhaust tube vortex are largely separated from the flame zone, and therefore, presumably, have no direct effect on the flame. In the following, the effect of the PVC is first analyzed by means of phase-averaged OH-CL measurements. The results show a major influence of the PVC on the flame at all operating conditions. The interaction of PVC and flame is then studied in more detail by means of simultaneous PIV and OH-PLIF measurements.

During the present work, the repetition rate of these measurements was restricted to $5 \mathrm{kHz}$. This rate provides a sufficient temporal resolution for the case $P=10 \mathrm{~kW}$, but not for $P>=20 \mathrm{~kW}$. The study of the interaction is therefore presently limited to the case $P=10 \mathrm{~kW}$. Additional equipment providing repetition rates up to $10 \mathrm{kHz}$ recently became available. An investigation of PVC-flame interaction at $P=20$ and $35 \mathrm{~kW}$ using this equipment will be presented in a subsequent study [43].

\subsection{Coupling between PVC and heat release}

The coupling between PVC and heat release is characterized using conditional averages of $\mathrm{OH}-\mathrm{CL}$ with respect to the phase angle of the PVC precession. The phase angle $\varphi$ was determined using the pressure signals as described in Sect. 2.3.5. For each thermal power, the conditional average for $\varphi=0^{\circ}$ is shown in Fig. 13. The images reveal a zone of heat release that is, like the PVC, located along a helix in the ISL. The averages at the other phase angles (not shown) correspond to a rotation of this helical structure around the central axis. The conditional averages of $\mathrm{OH}-\mathrm{CL}$ thus indicate that a significant part of the heat release is coupled to the PVC. The coupling persists over a large range of thermal powers, although the flame shape changes considerably in this range.

\subsection{Simultaneous PIV and OH-PLIF measurements}

In order to study the mechanisms of the vortex-flame interaction in more detail, velocity fields and flame structures are measured simultaneously using PIV and $\mathrm{OH}-$ PLIF. At $P=10 \mathrm{~kW}$, a series of 5000 measurements was aquired with a repetition rate of $5 \mathrm{kHz}$ as described in Sect. 2.3.3. An example of a single combined measurement is shown in Fig. 14. In the flow field, a zig-zag arrangement of vortices appears in the ISL (white arrows), which represent the helical PVC. Above the nozzle exit, the lower stagnation point (LSP) can be seen (red dot).

In the grayscale OH-PLIF image, different zones within the flame can be distinguished depending on the level of $\mathrm{OH}$. Regions without $\mathrm{OH}$ (black) represent gas with low or medium temperature $(T<1500 \mathrm{~K})$, i.e., unburned gas with possible admixture of burned gas. High levels of $\mathrm{OH}$ (light gray to white) indicate superequilibrium $\mathrm{OH}$, which is formed in the reaction zones and has a half-life period of $\approx 1$ ms under atmospheric pressure [38]. Regions with medium and low levels of $\mathrm{OH}$ (medium and dark gray) represent burned gas whose $\mathrm{OH}$ concentration has decayed toward equilibrium while it was transported away from the reaction zone. The equilibrium $\mathrm{OH}$ concentration increases with temperature and as the stoichiometric condition is approached [38].

For further characterization of the flame, it is desirable to determine the location of the reaction zones. As discussed above, the $\mathrm{OH}$ level across a reaction zone rises steeply from zero (unburned gas) to a superequilibrium level. The gradient of $\mathrm{OH}$ across the reaction zone is therefore significantly higher than in other regions of the flame. This effect can be used to (approximately) identify reaction zones from the gradient of the OH-PLIF image $[38,39]$. Similar to previous studies $[14,39]$, the reaction zone is identified in this work using a Sobel gradient filter and a subsequent threshold binarization. For the present example, the locations of reaction zones obtained with this method are shown in Fig. 15. The method is further used in the phase-averaged analysis in Sect. 5.4.

Two typical regions where reactions take place are highlighted in the enlarged views in Fig. 14. First, a reaction zone is found at the stagnation line above the nozzle exit (marked with red dots). At this line, the opposed flows of 


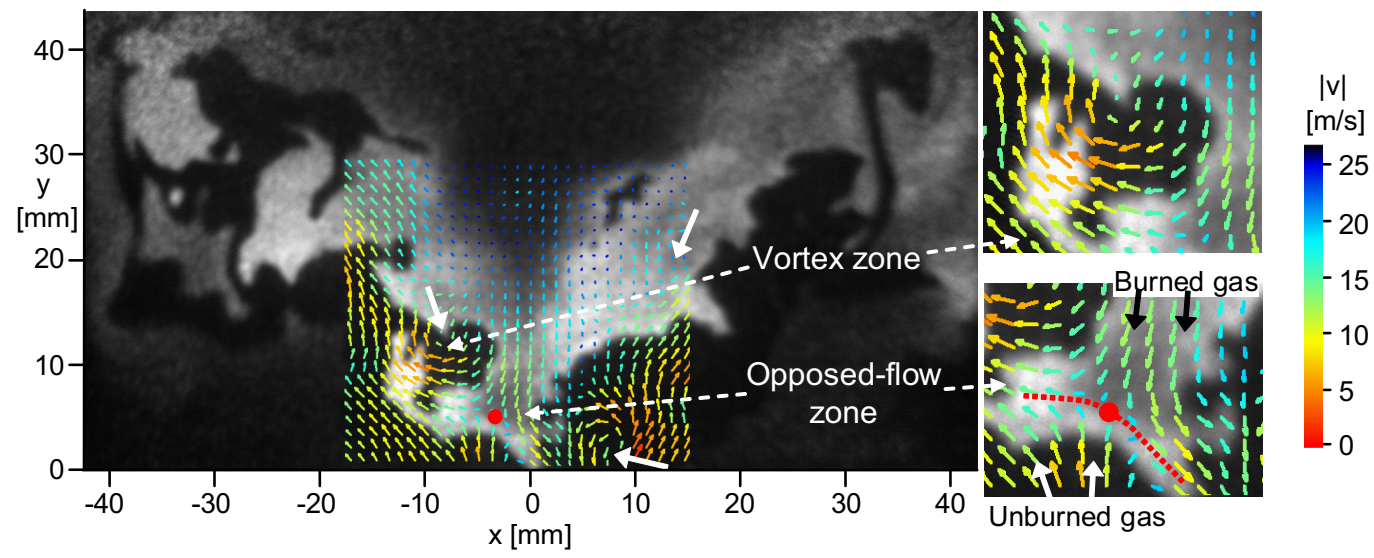

Figure 14: Simultaneous PIV and OH-PLIF measurement at $P=10 \mathrm{~kW}$. Vortex positions are marked with arrows, and the red dot indicates the position of the LSP.

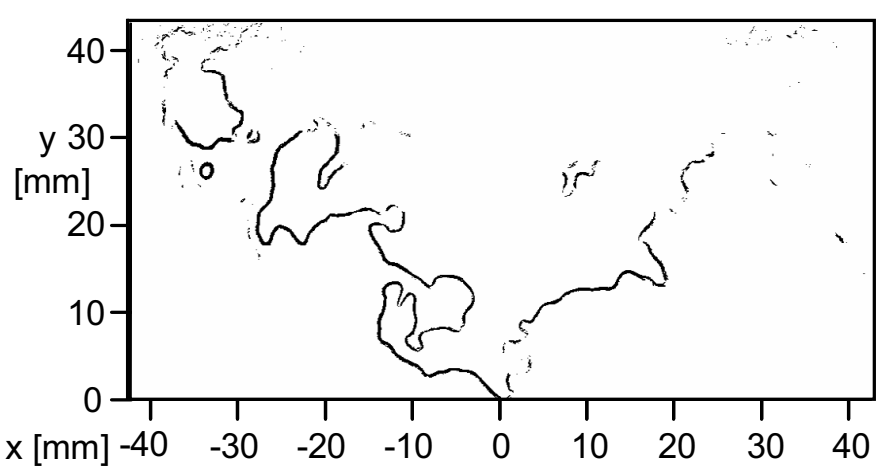

Figure 15: Reaction zone structure determined from the gradient of the OH-PLIF image in Fig. 14.

hot burned gas from the IRZ and unburned gas from the nozzle collide frontally. The burned gas supplies heat and radicals to the fresh gas and thus facilitates its ignition. Secondly, reaction zones are found near the vortices. It can be seen that the vortex on the left side rolls up the reaction zone, and thereby leads to an enlarged flame surface. The border between burned and unburned gas lies in the outer zone of the vortex with differential rotation (cf. Sect. 4.5), which causes increased mixing of burned and unburned gas.

Figure 16 presents a series of PIV and OH-PLIF measurements that show the temporal evolution of the situation in Fig. 14, with a period between measurements of $\Delta t=0.2 \mathrm{~ms}$. The flow field shows the downstream motion of the vortices (each marked with an arrow) along the ISL. The downstream motion is the two-dimensional representation of the rotation of the helical PVC around the central axis. At $t=0.8 \mathrm{~ms}$, another vortex appears on the left-hand side and subsequently propagates downstream. Furthermore the motion of the stagnation points (red dots), which is coupled to the vortex motion (cf. Sect. $4.3)$, can be seen.
The OH-PLIF image sequence shows the corresponding dynamics of the flame. At $t=0 \mathrm{~ms}$, the left-hand vortex deflects the burned gas from the stagnation point towards the left-hand side. In the following images $(t=0.2 \mathrm{~ms}$ and $t=0.4 \mathrm{~ms})$, the deflected burned gas is further rolled up by the vortex. The differential rotation in the outer vortex zone (cf. Sect. 4.5) enlarges the boundary between burned and unburned gas, which increases the supply of heat and radicals to the unburned gas and therefore promotes ignition of the unburned gas. Starting from $t=0.4$ $\mathrm{ms}$, the $\mathrm{OH}$ levels in the region around the vortex increase significantly, which indicates that reactions start taking place. Subsequently, the region of high $\mathrm{OH}$ levels becomes larger and propagates downstream together with the vortex. At the same time, the elongated region of unburned gas between the vortex and the IRZ decreases in size due to the reaction at its boundaries. Furthermore, at $t=0.6$ ms another vortex starts to roll-up burned gas towards the right-hand side of the nozzle. It thereby initiates a similar dynamics of the reaction zone as that seen on the left-hand side before. In the following frames (not shown), similar vortex-induced dynamics of the flame periodically takes place on the left- and right-hand sides. The image sequence also points out the important role of the stagnation points. It is seen that reaction zones are always located close to these points, where burned and unburned gas collide.

The effect of opposed flows of burned and unburned gas is further highlighted in the instantaneous PIV and OH-PLIF measurement shown on the left side of Fig. 17. On the right side, the figure additionally shows the corresponding location of reaction zones (determined from the gradient of $\mathrm{OH}$ ) and the principal compressive strain rate $S_{c}$ ( $S_{c}$ is the lower eigenvalue of the symmetric part of the $2 \mathrm{D}$ velocity gradient tensor, or zero if both eigenvalues are positive). It can be seen that high values of $\left|S_{c}\right|$ are not only found in the opposed-flow zone at the flame base, but also along elongated regions around the vortices. Re- 

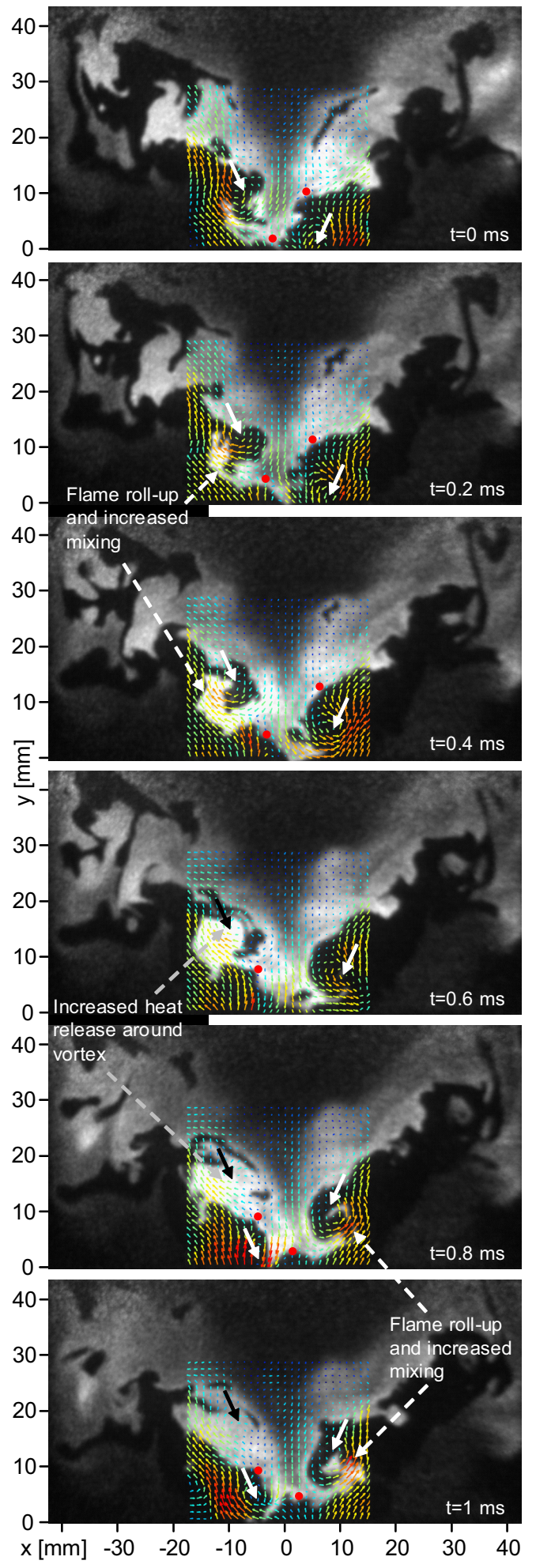

Figure 16: Sequence of simultaneous PIV and OH-PLIF measurements showing the interaction of PVC and flame. Vortex centers are marked with arrows, and red dots indicate the position of stagnation points. The vector color scale is the same as in Fig. 14. markably, the reaction zone often coincides with these regions of high compressive strain rate. This result indicates that the PVC can affect the location of the reaction zone via the compressive strain that it causes in these regions. The observed coincidence of high compressive strain and reaction zone was also found in a study of turbulent nonpremixed jet flames [40]. As discussed in this and other studies $[41,42]$, scalar dissipation rate plays an important role in this context.

\subsection{Phase-averaged analysis}

For a more stringent analysis of the effect of the PVC on the flame, instantaneous PIV and OH-PLIF measurements are conditionally averaged with respect to the phase angle $\varphi$ of the PVC precession. In this way, all fluctuations that are not correlated to the phase of the PVC are canceled out, and only the effects that are directly correlated with the PVC remain. The following analysis is based on a series of 4096 measurements, which were aquired with a repetition rate of $5 \mathrm{kHz}$ as described in Sect. 2.3.3. The phase angle $\varphi_{i}$ is determined for each velocity field as described in Sect. 4.2. For each OH-PLIF measurement, the structure of the reaction zone is determined from the gradient of $\mathrm{OH}$ (see Sect. 5.3). Phase averages are then calculated for the OH-PLIF images and the reaction zone structure at eight phases $\left(0^{\circ} \pm 22.5^{\circ}, 45^{\circ} \pm 22.5^{\circ}, 90^{\circ} \pm 22.5^{\circ}, \ldots\right.$, $315^{\circ} \pm 22.5^{\circ}$.

The phase-averaged dynamics of the velocity field was already discussed in Sect. 4.3 (Fig. 8). The corresponding dynamics of the flame are shown in the OH-PLIF images (top) and reaction zone structures (bottom) in Fig. 18 for $\varphi=0^{\circ}, 45^{\circ}, 90^{\circ}$ and $135^{\circ}$. The averages for $\varphi=180^{\circ}, 225^{\circ}$, $270^{\circ}$ and $315^{\circ}$ are equivalent but mirrored at the central axis $(x=0 \mathrm{~mm})$. The vortex centers and the stagnation points are marked with crosses and red dots, respectively.

The phase-averaged flame structures show that the PVC acts on the flame in two ways. Firstly, high reaction rates occur near the stagnation points. As discussed with the time-resolved measurements, the opposed flow of hot burned gas from the IRZ and unburned gas from the nozzle provides an efficient supply of heat and radicals to the fresh gas, and thereby supports reaction.

Secondly, the PVC leads to flame roll-up and convective mixing due to the differential rotation in the outer vortex zone (cf. Sect. 4.5). This can be seen in the OH-PLIF images starting at $\varphi=90^{\circ}$, where the vortex on the right side rolls up hot burned gas (black dashed arrow) and unburned gas (white dashed arrow). The roll-up leads to an enlarged flame surface and thus to overall increased reaction rates [10]. Furthermore the enlarged interface leads to an increased mixing of burned and unburned gas [31, 33, 34], which enhances the subsequent ignition of unburned gas in the ISL. Similar effects of flame roll-up, mixing and ignition were already discussed for the time-resolved measurements in Sect. 5.3. The fact that they appear in a similar way in the phase averages confirms that they are linked to the PVC. In addition to the processes seen in the 

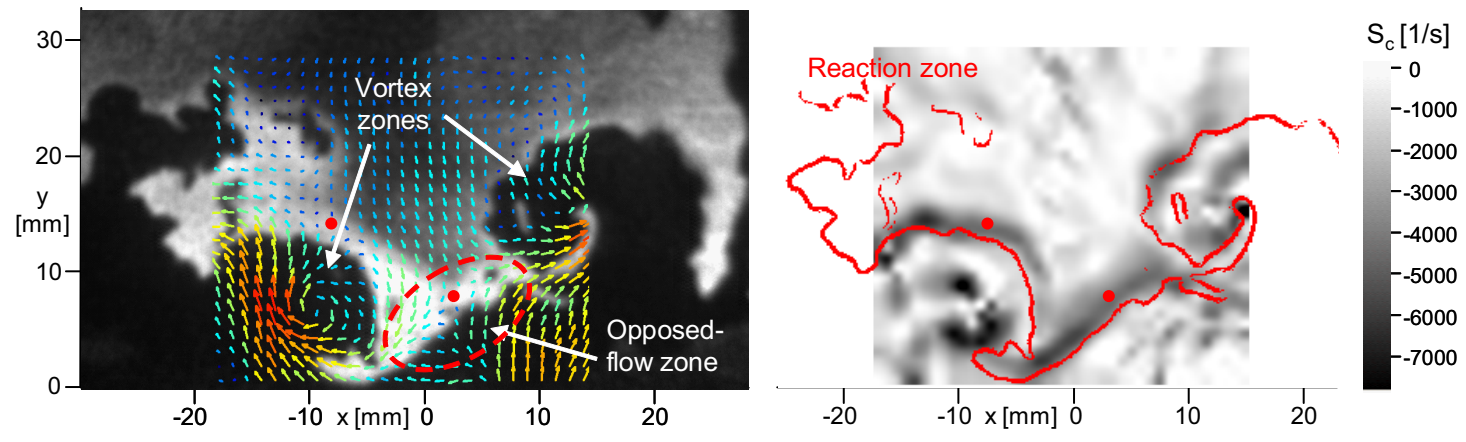

Figure 17: Simultaneous PIV and OH-PLIF measurement (left) with corresponding location of reaction zones and principal compressive strain rate $S_{c}$ (right). Red dots indicate the position of stagnation points. The vector color scale is the same as in Fig. 14 .

measurement plane, flame propagation may also take place in the out-of-plane direction as discussed in Sect. 5.5.

The OH-PLIF images also show that reacting and burned gases are recurrently deflected away from the lower stagnation point towards the right side $\left(\varphi=0^{\circ}\right.$ and $\left.\varphi=45^{\circ}\right)$ and left side $\left(\varphi=135^{\circ}\right)$. Subsequently roll-up, mixing and ignition take place in the ISL as discussed above. In this way, the reaction zone at the stagnation point serves as an ignition source for the reaction in the ISL, and thus is an essential element in the mechanism of flame stabilization. The observation that the $\mathrm{PVC}$ induces reaction both at the stagnation points and in the ISL, demonstrates the overall important role of the $\mathrm{PVC}$ in the stabilization of the flame.

\subsection{D structure of the reaction zone}

In Fig. 18 (bottom), phase-averaged 2D structures of the reaction zone were shown. Considering the phase angle $\varphi$ as a rotation angle, the 3D structure of the reaction zone can be reconstructed as was done with the flow field in Sect. 4.4. The result of the $3 \mathrm{D}$ reconstruction is shown as an isosurface plot in Fig. 19. Because of its small-scale filamentous texture, an additional smoothing of the reaction zone was performed before calculation of the isosurface.

The isosurface plot shows that heat release mainly takes place in the ISL. In particular, a helical flame zone along the $\mathrm{PVC}$ and a flat zone in the opposed-flow region can be identified. The existence of these zones and the mechanisms that lead to their formation have already been discussed in Sects. 5.3 and 5.4. Nevertheless, the 3D view provides a clearer characterization of the flame zone topology. For example, the helical structure of the flame zone in the ISL is now clearly visible. This is a direct link to the phase-averaged OH-CL measurements (Fig. 13), where such helical flame zones also appear. The elongate helical structure also suggests that the flame preferably propagates along the vortex axis. This may be caused by the low strain rates in the vortex core (cf. Sect. 4.5). The phenomenon of preferential flame propagation along a vortex core has been studied in more detail by, e.g., Hasegawa et al. [28] and Ishizuka et al. [29].
Furthermore, the connection of the opposed-flow zone and the helical zone in the lower part of the flame $(y<15$ $\mathrm{mm})$ can be seen. This further supports the interpretation that the opposed-flow zone serves as an ignition source for the reaction in the ISL. In the regions of the other two vortex structures that were found in Sect. 4.4, namely the vortex in the OSL and the exhaust tube vortex, no considerable heat release takes place. It is therefore concluded that they do not directly contribute to flame stabilization.

\section{Summary and conclusions}

The interaction of a helical precessing vortex core (PVC) with turbulent swirl flames in a gas turbine model combustor was studied experimentally. The combustor was operated with air and methane at atmospheric pressure and thermal powers from 10 to $35 \mathrm{~kW}$. The flow field was characterized using particle image velocimetry (PIV), and the dominant unsteady vortex structures were determined by means of proper orthogonal decomposition. For all operating conditions, a PVC was detected in the shear layer of the inner recirculation zone (IRZ). In addition, a corotating helical vortex in the outer shear layer (OSL) and a central vortex originating in the exhaust tube were found.

$\mathrm{OH}$ chemiluminescence (CL) images showed that the flames are mainly stabilized in the inner shear layer (ISL), where also the PVC is located. Phase-averaged images of OH-CL showed that for all conditions, a major part of heat release takes place in a helical zone that is coupled to the PVC. The mechanisms of the interaction between PVC and flame were then studied for the case $P=10 \mathrm{~kW}$ using simultaneous PIV and OH-PLIF measurements with a repetition rate of $5 \mathrm{kHz}$. The measurements showed that the PVC causes a regular sequence of flame roll-up, mixing of burned and unburned gas, and subsequent ignition of the mixture in the ISL. These effects are directly linked to the periodic vortex motions.

A phase-averaged analysis of the flow field showed that the PVC further induces an unsteady lower stagnation point that is not present in the average flow field. The motion of the stagnation point is linked to the periodic 


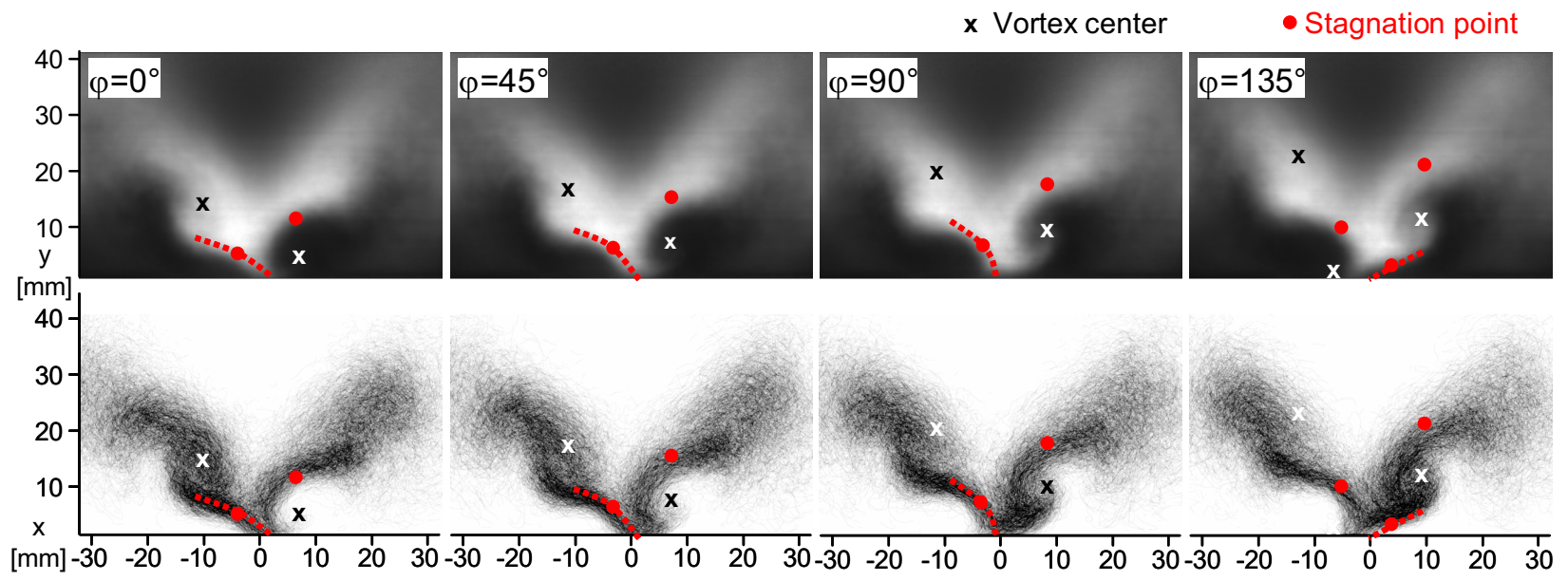

Figure 18: Phase averages of OH-PLIF distribution (top) and reaction zone structure (bottom) for $P=10 \mathrm{~kW}$.

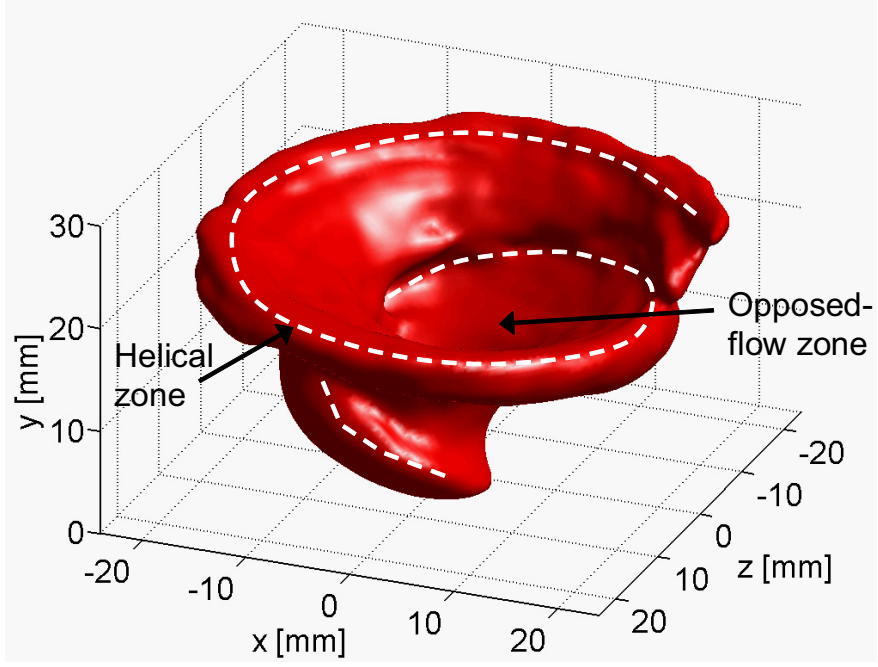

Figure 19: 3D structure of reaction zone for $P=10 \mathrm{~kW}$.

precession of the PVC. Near this point burned and unburned gas collide frontally and a significant amount of heat release takes place. The flame dynamics near this point is also coupled to the PVC. In this way, a part of the reaction zone is periodically drawn from the stagnation point into the ISL, and thus serves as an ignition source for the reactions in this layer. In total, the effects in the ISL and at the stagnation point showed that the PVC plays an essential role in the stabilization mechanism of the turbulent swirl flames. In contrast to the PVC, the vortices in the OSL and near the exhaust tube have no direct effect on the flame since they are located outside the flame zone.

During the present work, the repetition rate of PIV and OH-PLIF was restricted to $5 \mathrm{kHz}$. This rate provides a sufficient temporal resolution for the case $P=10 \mathrm{~kW}$, but not for $P>=20 \mathrm{~kW}$. Recently, additional equipment providing repetition rates up to $10 \mathrm{kHz}$ became available. An investigation of PVC-flame interaction at $P=20$ and 35 $\mathrm{kW}$ using this equipment will be presented in a subsequent study [43].

\section{Appendix A. Precessing vortex cores in gas tur- bine combustors: Literature survey}

A survey of literature about PVCs in GT-typical swirl combustors is presented in Table A.2. It can be seen that PVCs were found both in experimental and numerical studies, and they were encountered under reacting as well as non-reacting conditions. Sometimes a PVC found in a non-reacting case disappears when the flame is present. In most cases PVCs appear as a single helical vortex in the ISL, but double helical structures in the ISL are sometimes also reported. An additional secondary helical vortex in the OSL was found in some cases. Furthermore, influences of pilot flames, central jets, co- and counter-swirling flows, and combustion chamber geometry on the PVC have been observed.

The reported swirl numbers may have been calculated from the geometry of the swirler, or determined from velocity profiles. The precession frequency $f$ of the PVC is represented by the Strouhal number $\mathrm{St}=\frac{f d}{u}$, which is based on the nozzle diameter $d$ and the axial velocity $u$ averaged over the nozzle cross-section. A large variation is found in the observed Strouhal numbers, which may arise from different reasons. First, nozzles are sometimes contoured, and therefore the choice of the nozzle diameter $d$ is ambiguous. Moreover, some nozzles have a major central bluff body, such that the circular nozzle is reduced to an annular gap. In this case, both $d$ and $u$ are not well-defined. 


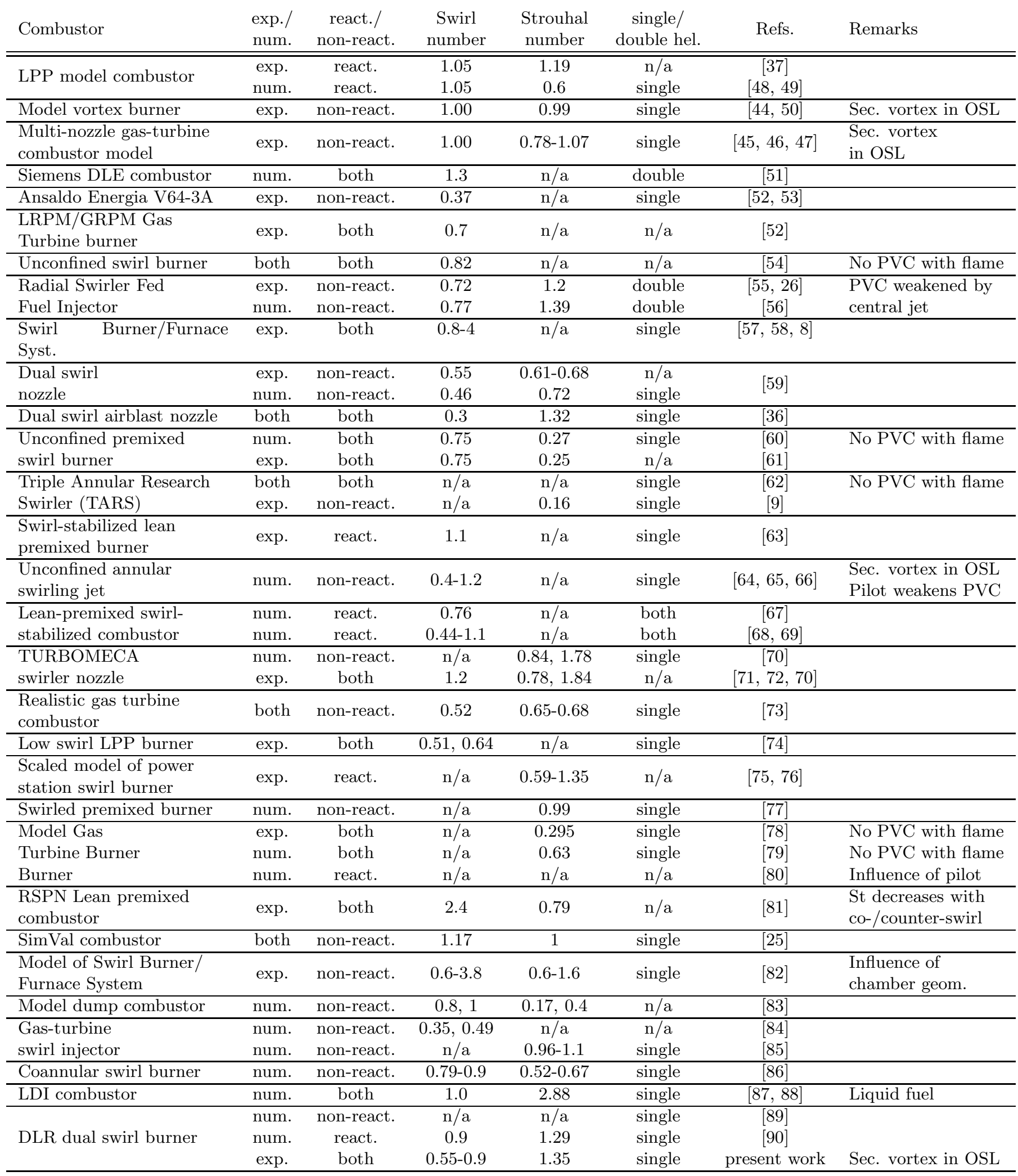

Table A.2: Literature survey of PVCs in gas turbine combustors 


\section{References}

[1] W. Meier, I. Boxx, M. Stöhr, C. D. Carter, Exp. Fluids 49 (2010) 865-882.

[2] N. Syred, Prog. Energy. Combust. Sci. 32 (2006) 93-161.

[3] W. Meier, X.R. Duan, P. Weigand, Combust. Flame 144 (2006) 225-236.

[4] A. R. Masri, P. A. M. Kalt, Y. M. Al-Abdeli, R. S. Barlow, Combust. Theor. Model. 11 (2007) 653-673.

[5] U. Stopper, M. Aigner, H. Ax, W. Meier, R. Sadanandan, M. Stöhr, A. Bonaldo, Exp. Therm. Fluid Sci. 34 (2010) 396-403.

[6] N. Syred, J. M. Beér, Proc. Combust. Inst. 14 (1973) 537-550.

[7] N. Syred, A. K. Gupta, J. M. Beér, Proc. Combust. Inst. 15 (1975) 587-597.

[8] N. Syred, W. Fick, T. O'Doherty, A. J. Griffiths, Combust. Sci. Tech. 125 (1997) 139-157.

[9] G. Li, E. J. Gutmark, 42nd AIAA Science Meeting and Exhibit (2004) AIAA-2004-0133.

[10] P. H. Renard, D. Thévenin, J. C. Rolon, S. Candel, Prog. Energy Combust. Sci. 26 (2000) 225-282.

[11] D. Thévenin, P. H. Renard, G. J. Fiechtner, J. R. Gord, J. C. Rolon, Proc. Combust. Inst. 28 (2000) 2101-2108.

[12] T. Echekki, H. Kolera-Gokula, Phys. Fluids 19 (2007) 043604.

[13] H. Reddy, J. Abraham, Combust. Flame 158 (2011) 401-415.

[14] I. Boxx, M. Stöhr, C. Carter, W. Meier, Combust. Flame 157 (2010) 1510-1525.

[15] A. M. Steinberg, I. Boxx, M. Stöhr, C. D. Carter, W. Meier, Combust. Flame 157 (2010) 2250-2266.

[16] M. Stöhr, I. Boxx, C. D. Carter, W. Meier, Proc. Combust. Inst. 33 (2011) 2953-2960.

[17] M. Stöhr, R. Sadanandan, W. Meier, Exp. Fluids 51 (2011) 1153-1167.

[18] P. Weigand, W. Meier, X. R. Duan, W. Stricker, M. Aigner, Combust. Flame 144 (2006) 205-224.

[19] N. J. Lawson, J. Wu, Meas. Sci. Technol. 8 (1997) 1455-1464.

[20] Y. Hardalupas, M. Orain, Combust. Flame 139 (2004) 188-207.

[21] G. Berkooz, P. Holmes, J. L. Lumley, Annu. Rev. Fluid Mech. 25 (1993) 539-575.

[22] P. Chakraborty, S. Balachandar, R. J. Adrian, J. Fluid Mech. 535 (2005) 189-214.

[23] J. Zhou, R. J. Adrian, S. Balachandar, T. M. Kendall, J. Fluid Mech. 387 (1999) 353-396.

[24] M. D Turrell, P. J. Stopford, K. J. Syed, E. Buchanan, Proc. ASME Turbo Expo (2004) GT2004-53112.

[25] P. A. Strakey, M. J. Yip, J. Fluids Eng. 129 (2007) 942-953.

[26] A. Spencer, J. J. McGuirk, K. Midgley, J. Eng. Gas Turb. Power 130 (2008) 021503.

[27] T. Poinsot, D. Veynante, S. Candel, J. Fluid Mech. 228 (1991) 561-606.

[28] T. Hasegawa, S. Michikami, T. Nomura, D. Gotoh, T. Sato, Combust. Flame 129 (2002) 294-304.

[29] S. Ishizuka, Prog. Energy Combust. Sci. 28 (2002) 477-542.

[30] B. M. Cetegen, W. A. Sirignano, Combust. Sci. Tech. 72 (1990) 157-181.

[31] B. M. Cetegen, Exp. Fluids 40 (2006) 967-976.

[32] J. P. Crimaldi, J. R. Cadwell, J. B. Weiss, Phys. Fluids 20 (2008) 073605.

[33] P. Flohr, J. C. Vassilicos, J. Fluid Mech. 348 (1997) 295-317

[34] K. Bajer, A. P. Bassom, A. D. Gilbert, J. Fluid Mech. 437 (2001) 395-411.

[35] P. H. Renard, J. C. Rolon, D. Thévenin, S. Candel, Combust. Flame 117 (1999) 189-205.

[36] P. Fokaides, M. Wei, M. Kern, N. Zarzalis, Flow Turb. Combust. 83 (2009) 511-533.

[37] P. M. Anacleto, E. C. Fernandes, M. V. Heitor, S. I. Shtork, Combust. Sci. Tech. 175 (2003) 1369-1388.

[38] R. Sadanandan, M. Stöhr, W. Meier, Appl. Phys. B 90 (2008) 609-618.

[39] A. E. Bayley, Y. Hardalupas, A. M. K. P. Taylor, Exp. Fluids, in press, DOI 10.1007/s00348-011-1181-4.

[40] J. E. Rehm, N. T. Clemens, 37th Aerospace Sciences Meeting and Exhibit (1999) AIAA-99-0676.
[41] P.S. Kothnur, N.T. Clemens, Phys. Fluids 17 (2005) 125104.

[42] J. H. Frank, S. A. Kaiser, Exp. Fluids 44 (2008) 221-233.

[43] M. Stöhr, C. M. Arndt, W. Meier, Proc. Combust. Inst. (submitted).

[44] S. I. Shtork, C. E. Cala, E. C. Fernandes, Exp. Therm. Fluid Sci. 31 (2007) 779-788

[45] B. Böhm, A. Dreizler, M. Gnirss, C. Tropea, J. Findeisen, H.-P. Schiffer, Proc. ASME Turbo Expo (2007) GT2007-27111.

[46] M. Gnirß, C. Tropea, Exp. Fluids 45 (2008) 643-656.

[47] S. Jakirlic, B. Kniesner, G. Kadavelil, M. Gnirß, C. Tropea, Flow Turb. Combust. 83 (2009) 425-448.

[48] C. Duwig, L. Fuchs, Phys. Fluids 19 (2007) 075103.

[49] P. Iudiciani, C. Duwig, Flow Turb. Combust. 86 (2011) 639-666.

[50] C. E. Cala, E. C. Fernandes, M. V. Heitor, S. I. Shtork, Exp. Fluids 40 (2006) 267-276.

[51] G. Bulat, P. Stopford, M. Turrell, D. Frach, E. Buchanan, M. Stöhr, Proc. ASME Turbo Expo (2009) GT2009-59721.

[52] D. Accornero, M. Caruggi, A. Nilberto, F. Pittaluga, Proc. ASME Turbo Expo (2011) GT2011-46490.

[53] M. Caruggi, A. Nilberto, F. Bonzani, Proc. ASME Turbo Expo (2008) GT2008-50592.

[54] A. De, S. Zhu, S. Acharya, J. Eng. Gas Turb. Power 132 (2010) 071503.

[55] K. Midgley, A. Spencer, J. J. McGuirk, Proc. ASME Turbo Expo (2007) GT2007-27924.

[56] D. Dunham, A. Spencer, J. J. McGuirk, M. Dianat, J. Eng. Gas Turb. Power 131 (2009) 011502.

[57] W. Fick, A. J. Griffiths, T. O'Doherty, Opt. Diagn. Eng. 2 (1997) 19-31.

[58] D. Froud, T. O'Doherty, N. Syred, Combust. Flame 100 (1995) 407-412.

[59] F. Flemming, C. Olbricht, B. Wegner, A. Sadiki, J. Janicka, F. Bake, U. Michel, B. Lehmann, I. Röhle, Flow Turb. Combust. 75 (2005) 3-27.

[60] M. Freitag, J. Janicka, Proc. Combust. Inst. 31 (2007) 14771485.

[61] C. Schneider, A. Dreizler, J. Janicka, Flow Turb. Combust. 74 (2005) 103-127.

[62] C. Fureby, F. F. Grinstein, G. Li, E. J. Gutmark, Proc. Combust. Inst. 31 (2007) 3107-3114.

[63] D. Galley, S. Ducruix, F. Lacas, D. Veynante, Combust. Flame 158 (2011) 155-171.

[64] M. Garcia-Villalba, J. Fröhlich, W. Rodi, Phys. Fluids 18 (2006) 055103.

[65] M. Garcia-Villalba, J. Fröhlich, Int. J. Heat Fluid Flow 27 (2006) 911-923.

[66] M. Garcia-Villalba, J. Fröhlich, W. Rodi, J. Eng. Gas Turb. Power 129 (2007) 377-386.

[67] Y. Huang,H.-G. Sung, S.-Y. Hsieh, V. Yang, J. Propul. Power 19 (2003) 782-794.

[68] Y. Huang, V. Yang, Proc. Combust. Inst. 30 (2005) 1775-1782.

[69] Y. Huang, S. Wang, V. Yang, AIAA J. 44 (2006) 724-740.

[70] B. Wegner, M. Staufer, A. Sadiki, J. Janicka, Flow Turb. Combust. 79 (2007) 389-403.

[71] B. Janus, A. Dreizler, J. Janicka, Flow Turb. Combust. 75 (2005) 293-315.

[72] B. Janus, A. Dreizler, J. Janicka, Proc. Combust. Inst. 31 (2007) 3091-3098.

[73] P. Jochmann, A. Sinigersky, M. Hehle, O. Schäfer, R. Koch, H.-J. Bauer, Int. J. Heat and Fluid Flow 27 (2006) 192-203.

[74] M. Legrand, J. Nogueira, A. Lecuona, S. Nauri, P. A. Rodriguez, Exp. Fluids 48 (2010) 901-913.

[75] T O'Doherty, D. Froud, C. J. Bates, N. Syred, Proc Inst Mech Eng Part A: J Power Energy 208 (1994) 89-101.

[76] N. Syred, T. O'Doherty, D. Froud, Proc Inst Mech Eng Part A: J Power Energy 208 (1994) 27-36.

[77] S. Roux, G. Lartigue, T. Poinsot, U. Meier, C. Berat, Combust. Flame 141 (2005) 40-54.

[78] K.-U. Schildmacher, R. Koch, H.-J. Bauer, Flow Turb. Combust. 76 (2006) 177-197.

[79] L. Selle, L. Benoit, T. Poinsot, F. Nicoud, W. Krebs, Combust. 
Flame 145 (2006) 194-205.

[80] A. X. Sengissen, A. V. Giauque, G. S. Staffelbach, M. Porta, W. Krebs, P. Kaufmann, T. J. Poinsot, Proc. Combust. Inst. 31 (2007) 1729-1736.

[81] K. K. Singh, L. Mongeau, S. H. Frankel, J. P. Gore, AIAA J. 45 (2007) 651-661.

[82] A. Valera-Medina, N. Syred, A. Griffiths, Combust. Flame 156 (2009) 1723-1734.

[83] P. Wang, X. S. Baia, M. Wessman, J. Klingmann, Phys. Fluids 16 (2004) 3306-3324.

[84] S. Wang, S.-Y. Hsieh, V. Yang, Phys. Fluids 17 (2005) 045106.

[85] S. Wang, V. Yang, G. Hsiao, S.-Y. Hsieh, H. C. Mongia, J. Fluid Mech. 583 (2007) 99-122.

[86] P. Wang, J. Fröhlich, Proc. 6th Int. Symposium on Turbulence and Shear Phenomena, Seoul, Korea (2009) 557-562.

[87] N. Patel, M. Kirtas, V. Sankaran, S. Menon, Proc. Combust. Inst. 31 (2007) 2327-2334

[88] N. Patel, S. Menon, Combust. Flame 153 (2008) 228-257.

[89] A. Widenhorn, B. Noll, M. Stöhr, M. Aigner, Second Symposium on Hybrid RANS-LES Methods, Corfu, Greece (2007).

[90] A. Widenhorn, B. Noll, M. Aigner, Proc. ASME Turbo Expo (2009) GT2009-59038. 